\title{
Las variaciones en los contratos de construcción: precisiones sobre su noción y causas $^{(*)}$
}

\section{Variations in Construction Contracts: Precisions about their Notion and Causes}

\author{
Walter Humberto Vásquez Rebaza ${ }^{(*)}$ \\ Pontificia Universidad Católica del Perú
}

\begin{abstract}
Resumen: Uno de los aspectos más relevantes de los proyectos de construcción es el de sus variaciones. Se trata de situaciones que si bien generan una serie de consecuencias negativas para los involucrados y constituyen el caldo de cultivo de reclamos y controversias, resultan ciertamente inevitables en la industria constructiva. En el presente artículo (que forma parte de una obra en curso) analizaremos dos cuestiones fundamentales sobre las variaciones: su delimitación conceptual y las causas a las que obedece. En líneas generales, creemos que un mejor entendimiento del fenómeno permitirá brindar soluciones adecuadas y coherentes a su problemática empírica. La importancia de un trabajo de esta naturaleza deriva del vacío existente a nivel legislativo, doctrinal y jurisprudencial en el Perú. En efecto, la regulación del contrato de obra contenida en el Código Civil no dedica un tratamiento orgánico a las variaciones. No obstante, ciertas disposiciones del mencionado cuerpo normativo (así como otras incluidas en disciplinas sectoriales) se refieren a los cambios asignándoles importantes efectos jurídicos.
\end{abstract}

Palabras Clave: Contratos de construcción - Variaciones - Modelos Comparados Sistema Jurídico Peruano

\begin{abstract}
One of the most important aspects of construction projects are their variations. These are situations that generate a series of negative consequences for those involved and constitute the breeding ground for claims and controversies, are inevitable in the construction industry. In the present article we will analyze two fundamental questions about variations: their conceptual delimitation and its causes. In general terms, we believe that a better understanding of the phenomenon will allow providing adequate and coherent solutions to the problem. The importance of this article derives from the vacuum at the legislative, doctrinal and jurisprudential levels in Peru. In effect, the regulation of the work contract contained in the Civil Code does not devote an organic treatment to variations. However, certain provisions of the mentioned normative body (as well as others included in sectoral disciplines) refer to the changes assigning them important legal effects.
\end{abstract}

Keywords: Construction Contracts - Variations - Compared Models - Peruvian Legal System

$\left(^{*}\right) \quad$ Nota del Editor: el artículo fue recibido el 7 de noviembre y aprobada su publicación el 21 de noviembre de 2018.

${ }^{* *}$ Abogado y Magíster por la Pontificia Universidad Católica del Perú. Profesor de Derecho Contractual en dicha Casa de Estudios y en la Universidad Nacional Mayor de San Marcos. Integrante de la delegación peruana en el Grupo para la Armonización del Derecho en América Latina (Gadal). 


\section{Introducción}

Uno de los puntos de mayor trascendencia en la problemática actual concerniente a los proyectos de construcción se encuentra dado por la presencia de variaciones en el alcance de trabajos del contratista, las cuales también suelen ser denominadas modificaciones o simplemente cambios.

Bien conocidas son las consecuencias del fenómeno tales como los sobrecostos, impactos en la remuneración, alteraciones en la secuencia constructiva, disrupciones, atrasos, ampliaciones de plazo y empleo de asunciones técnicas ${ }^{(1)}$. A menudo, dichas circunstancias vienen acompañadas por la reducción de la calidad y de la productividad de sus recursos, atrasos en los pagos a favor del contratista, daños a la reputación de las firmas involucradas, disminución de las condiciones de seguridad y dificultades en las relaciones entre profesionales (con la consiguiente necesidad de sustituirlos) (Arain \& Low 2003, 409-500) ${ }^{(2)(3)}$.

En ese sentido, no resulta difícil entender por qué las variaciones constituyen el caldo de cultivo de reclamos y controversias. $Y$ es que, de manera general, su incorporación altera la organización de intereses y el equilibrio económico convenido, ocasionando la imperiosa necesidad de reajustar aspectos como el precio, el plazo, las garantías y otros términos comerciales (Molina \& Ríos 2016, 142; Horgué 1997, 168).

Ahora bien, más que al plano fáctico, en el presente trabajo hemos querido remontarnos a la reconstrucción conceptual de algunas cuestiones fundamentales para un adecuando entendimiento de las variaciones. En ese sentido, intentaremos dar respuesta a las siguientes interrogantes: (i) ¿cuál es exactamente la noción de variaciones en el ámbito de los contratos de obra? y (ii) ¿cuáles son las razones que determinan el surgimiento de este fenómeno en los proyectos constructivos?

La importancia de una investigación de esta naturaleza deriva, en primer lugar, de que la regulación típica del contrato de obra contenida en el Código Civil peruano no dedica un tratamiento orgánico a dicho fenómeno. Empero, ciertas disposiciones del mencionado cuerpo normativo (así como otras, sectoriales) se refieren a las variaciones asignándoles importantes efectos jurídicos. A ello se aúna el preocupante vacío doctrinario y jurisprudencial existente en este ámbito.

En segundo lugar, se aprecia que las prácticas de la industria constructiva nacional e internacional conciben un conjunto de reglas aplicables a la categoría objeto de análisis, las cuales no necesariamente resultan compatibles con el ordenamiento positivo nacional. Por ende, creemos necesario realizar un contraste entre los referidos estatutos.

Al respecto, es importante advertir que los modelos comparados se ocupan primordialmente de las variaciones unilaterales (esto es, aquellas ordenadas por del comitente). Si bien las diferencias entre dicha categoría y las variaciones consensuales resultan relevantes; para efectos del presente trabajo nos moveremos en un ámbito de abstracción mayor, pues aludiremos al mínimo común existente entre los dos tipos de cambios aludidos. En otras palabras, las siguientes líneas englobarán tanto a las variaciones unilaterales como a las consensuales.

Finalmente, la construcción conceptual de la variación se valdrá del método aristotélico. Como se sabe, este último parte de reconocer el género próximo al que pertenece la categoría objeto de definición para luego hallar aquellas diferencias específicas que la individualizan y la aíslan del resto de componentes del género. Luego, la metodología descrita recurre a la delimitación negativa del concepto a definir, con el propósito de perfilar la construcción conceptual propuesta a través de su distinción de figuras afines.

\section{Causas de las variaciones en los proyectos de construcción}

La delimitación conceptual de la categoría objeto de análisis presupone la revisión de sus principales causas, es decir, de aquellos detonantes que, aunados a la inexorable intervención del tiempo en los proyectos constructivos (Hibberd 1986, 6; Podetti 2004, 321), generan el terreno propicio para la germinación de variaciones.

Según los autores que se han dedicado a la materia, entre los factores determinantes de la proliferación de cambios en los proyectos constructivos se encuentran los siguientes ${ }^{(4)}$.

(1) Dichas asunciones a menudo se revelan como inexactas, dando lugar, a su vez, a la remoción y repetición de trabajos ejecutados. En la praxis transaccional dicho fenómeno suele ser conocido como re-trabajos.

(2) Tales situaciones determinan que, en cualquier proyecto de construcción, se suela prever y destinar una "suma de contingencia" a atender las eventuales variaciones, manteniendo intacto el costo total del mismo (Arain \& Low 2003, 498).

(3) Las consecuencias de las variaciones suelen ser de menor envergadura si se presentan en la etapa de diseño del proyecto antes que en la fase constructiva. Ello se debe a que en esta última etapa (i) existen más probabilidades de que se impacte las actividades subsecuentes y (ii) los eventuales reajustes deberán realizarse en un tiempo menor al ordinario.

(4) Resulta interesante advertir que, según estudios efectuados a nivel internacional, la razón más común de las variaciones se encuentra dada por los cambios en las especificaciones técnicas; mientras que los efectos de las vicisitudes naturales (normalmente ajenas al 
- Las limitaciones técnicas intrínsecas de la industria constructiva (Damonte citado por Ugas 2010, 388)(5);

- La constatación de que el diseño, la coordinación y la comunicación entre los interesados del proyecto no resultan perfectas (Hanna \& Swanson 2007, 60; Oladapo 2007, 35; Thomas, 2001, 10; De Almagro \& Klee 2017, 89)(6);

- El advenimiento de nuevas e inesperadas necesidades del comitente (o su cliente) durante el proceso constructivo (Oladapo 2007, 37; Adriaanse 2016, 201), incluyendo la fase de diseño (Arain \& Low 2003, 497);

- Los cambios en las condiciones de mercado (que podrían incidir en los parámetros del proyecto) y los desarrollos tecnológicos sobrevinientes (que podrían condicionar las decisiones del ingeniero) (Arain \& Low 2003, 497);

- La divergencia entre las condiciones del sitio previstas a la hora de realizar el diseño preliminar y aquellas reales, aun habiendo efectuado estudios previos (De Almagro \& Klee 2017, 89);

- Dificultades ligadas a la entrega área del emplazamiento y de sus accesos, a la secuencia de operaciones y a las restricciones en el tiempo de trabajo (Hibberd 1986, 7); y,

- El excesivo costo e indisponibilidad de los materiales de construcción (Callahan 2005, 19).

Otra opinión sintetiza el origen de las variaciones en las deficiencias (imputables o no a las partes) de los documentos técnicos, los problemas en los procesos constructivos (ya sea derivados de las mejoras del proyecto o de la reducción de su costo o plazo) o la simple conveniencia o estética juzgada por el comitente o sus asesores técnicos (Sergeant \& Wieliczko 2014, 3 y 17).

Como se advierte, es un lugar común catalogar a las deficiencias técnicas como uno de los más importantes eventos gatilladores de cambios. Los siguientes ejemplos nos podrían ilustrar sobre esta realidad.

En el marco de la implementación de un terminal portuario, un comitente celebra un contrato de construcción con cierto subcontratista. Para la realización de su alcance, el comitente elabora y entrega al contratista los planos y especificaciones técnicas. Entre otros componentes, los referidos documentos proyectan la construcción de una faja transportadora de minerales con cierto ángulo de inclinación (asociado estrechamente a la velocidad comercial esperada) y apoyada en seis pares de pilotes. Sin embargo, en el curso de la obra se advierte que para la consecución estable del referido ángulo se requerirá por lo menos dos pares de pilotes más (en total, ocho).

En cierta obra civil, se proyecta la construcción de una bocatoma en un emplazamiento individualizado con coordenadas georreferenciadas. El comitente (que a su vez elaboró el expediente técnico a través de un diseñador) encarga un contratista la ejecución de dicha obra civil. Es el caso que las muestras de terreno recogidas in situ por el contratista al momento de acceder al sitio determinaron que el suelo donde se habría de erigir la bocatoma contaba con una capacidad portante mucho menor a la contemplada en el estudio geológico adjunto al expediente técnico. Por consiguiente, si la obra se implementaba conforme a lo originalmente planificado, estaba destinada a su prematuro hundimiento y consiguiente inutilidad.

El punto en común de los casos descritos radica en que el cumplimiento del ángulo de inclinación de la faja y la propia existencia funcional de la bocatoma, respectivamente, requerirán de la introducción de variaciones en los planos y/o especificaciones primigenias. $Y$ ello en vista de las falencias en la información técnica y geológica originalmente generada y entregada al contratista ${ }^{(7)}$.

control de las partes) conforman la causa menos frecuente. Del mismo modo, la iniciativa del propietario se perfila como la principal fuente de cambios, mientras que la menos relevante, se encuentra dada por las iniciativas estatales o de las agencias regulatorias (Oladapo 2007, 39 y 40).

De otro lado, se ha puntualizado que el tipo y tamaño del proyecto no tiene un impacto significativo en la existencia de variaciones (Oladapo 2007, 35), es decir, estas últimas resultan frecuentes al margen de la magnitud de la obra constructiva de que se trate.

Como es evidente, las estadísticas explicitadas resultan meramente referenciales, en tanto su configuración concreta dependerá de la praxis transaccional y características de la industria de cada país.

(5) En opinión del autor, "las variaciones en el curso de la obra son el único instrumento que permite resolver la inevitable discrasia que se verifica en la actividad cotidiana de construcción entre obra proyectada y realización de la misma, a causa de los límites inherentes a la actividad de proyección".

(6) Esta dificultad se intensifica si se constata las frecuentes superposiciones de tareas entre los profesionales partícipes de los proyectos de construcción. Ello se da, por ejemplo, cuando un contratista de obra civil le advierte al comitente la necesidad de efectuar una variación en el diseño de una obra compleja, luego de lo cual el comitente le encarga al primero elaborar la ingeniería de dicha modificación. Ello resulta inadecuado no solo porque dicha tarea no se corresponde con el expertise del contratista en cuestión, sino también porque prescinde de la colaboración del tercero (proyectista o diseñador) que cuenta con una visión global de la ingeniería de las otras unidades del proyecto eventualmente impactadas.

(7) Para tal ejemplo, debe considerarse que el riesgo técnico no fue asumido por el contratista, a diferencia de lo que habría ocurrido en caso su alcance hubiese calificado como design \& build. 
Ahora bien, autores como Hibberd aseveran que las deficiencias técnicas no son necesariamente atribuibles a la impericia de las partes, sino que bien podrían deberse a circunstancias naturales de los ciclos de desarrollo del proyecto. $Y$ es que la dinámica de estos últimos supone una constante generación y flujo de nueva y más exacta información, la cual a menudo impulsa al comitente modificar los juicios de valor sobre el diseño (incluso en la etapa constructiva) $(1986,2)$. En palabras del autor:

“(...) las variaciones son directamente atribuibles a situaciones que no ocurrieron tal como fueron declaradas o previstas en los documentos contractuales. Esto ocurre ya sea porque las circunstancias realmente cambiaron o porque circunstancias en las cuales los documentos contractuales se basaron fueron malentendidas.

La anterior es una situación que podemos apreciar y comprender; sin embargo, posee dos aspectos distintos. En primer lugar, las circunstancias pueden cambiar de una forma tal, sobre la cual no se tiene control, que la documentación puede ser vista hoy como defectuosa. Alternativamente, las circunstancias pueden requerir que el cliente determine una forma de acción, siendo que dicha elección deriva en la creación de una variación" (Hibberd 1986, 2).

Conforme a este parecer, las variaciones pueden ser la consecuencia de concebir al diseño como un proceso constante que no solo se desarrolla previo al inicio de la construcción física, sino que se ejecuta incluso después de esta fase y hasta que ya no pueda incorporarse más cambios al proyecto. En ese sentido, el proceso de diseño no habrá sido completado cuando el equipo del proyectista efectúe su entregable, pues el contratista (que no es miembro formal de dicho equipo) es el responsable del último nivel de diseño en muchas (sino todas) las instancias (Hibberd 1986, 3-4; en el mismo sentido Steinberg 2017, 173) ${ }^{(8)}$.

Creemos que lo mencionado es una de las razones por las cuales las variaciones actualmente, prescindiendo de la imputabilidad de las partes, resultan inevitables en los proyectos constructivos.

Ahora bien, en vez de negar la natural necesidad de ciertas variaciones en los proyectos, los redactores de contratos de obra deberían aceptar plenamente esta realidad y dirigir sus esfuerzos a dotar al documento de reglas claras, realistas, operativas y eficientes respecto a la incorporación de cambios. Ello les permitiría a las partes lidiar oportunamente con el inevitable panorama descrito. De lo contrario, el comitente podría terminar recayendo en una situación de imputabilidad contractual o viéndose obligado a aceptar un producto inferior, a causa de su inaptitud para cambiarlo por el producto que ahora desea (Hibberd 1986, 10).

En otras palabras, si los profesionales encargados de elaborar contratos conciben al cambio únicamente como un suceso evitable e indeseable (por ser necesariamente patológico e irregular), le estarían dando la espalda a la realidad. Por el contrario, dichos redactores deben buscar favorecer la resiliencia del documento contractual, esto es, diseñar a este último de una manera tal que le permita su adaptación a las vicisitudes de diversa índole con las que se encontrarán las partes en la etapa de ejecución.

Por nuestra parte, además de las deficiencias técnicas y otras situaciones mencionadas anteriormente, consideramos que los siguientes pueden incorporarse al elenco de detonantes habituales de variaciones:

- la falsedad e inobservancia de declaraciones y garantías, así como el incumplimiento de obligaciones y cargas de las partes (especialmente aquellas que constituyen actividades precedentes de otras);

- la discontinuidad de los documentos contractuales iniciales debida a la demora en el proceso de negociación, frecuentemente influenciado por razones políticas y/o burocráticas;

- los cambios normativos y la demora en la emisión de licencias y permisos ambientales, regulatorios, arqueológicos asociados al sitio;

- la obsolescencia, inviabilidad e ilegalidad de componentes del proyecto y métodos de construcción originalmente previsto en los documentos contractuales; $y$,

las necesidades de financiamiento para la continuidad de proyectos, las cuales suelen requerir un análisis técnico de la bancabilidad de la propuesta de cambio $^{(9)}$

(8) Sin duda alguna, ello no excluye la posibilidad que el contratista delegue o, por lo menos, coordine diligentemente con el proyectista o diseñador cuando ello sea necesario para implementar un cambio en la ingeniería a cargo de estos últimos.

(9) Dicha situación origina la celebración de adendas de bancabilidad, que no son otra cosa que el nombre coloquial que reciben los documentos que canalizan este tipo de variaciones. Estos documentos hallan su razón de ser en los requerimientos de los asesores técnicos de los financistas, cuyo interés radica en la viabilidad del proyecto, sobre cuyos flujos suelen recaer las garantías de restitución del capital invertido.

Al respecto, cabe señalar que el actual Decreto Supremo 240-2018-EF (que aprueba el Reglamento del Decreto Legislativo 1362) prohíbe la suscripción de adendas de bancabilidad durante los tres primeros años contados a partir de la fecha de suscripción del Contrato, con el propósito de darle estabilidad y seriedad a los términos y condiciones iniciales.

Decreto Supremo 240-2018-EF. Artículo 135. "Límite temporal para la suscripción de modificaciones contractuales. 
Mención aparte amerita otra importante causa de las variaciones: la corrupción. En efecto, en los años recientes se ha vuelto un lugar común emplear adendas como un instrumento para incrementar irregularmente las utilidades de ciertos contratistas. En efecto, como podría ocurrir con toda categoría jurídica, en ocasiones el referido instrumento legal ha sido desnaturalizado de manera irregular, lo que constituye una situación del todo patológica, cuya erradicación resulta imperiosa. Sin embargo, ello no debería llevar a considerar al instrumento, adenda, o al concepto / variación como elementos en sí mismo dañinos.

Un detonante ulterior de los cambios en el alcance se encuentra dado por la necesidad de optimizar el proyecto a iniciativa del contratista, el cual bien podría buscar introducir (a través de iniciativas) mejoras tecnológicas, de proceso o acelerar los trabajos. Dichas situaciones frecuentemente se encuentran acompañadas de un ahorro de costos y/o de recursos para ambas partes del contrato de construcción. Este punto se encuentra estrechamente relacionado al concepto de "ingeniería de valor" (De Almagro \& Klee 2017, 90).

A manera de síntesis de este apartado, puede afirmarse que los cambios en los proyectos de construcción pueden ser agrupados en dos categorías, según hallen o no su origen en un evento detectable por alguno de los contratantes. En función al referido criterio, descriptivo antes que operativo, existirán causas de variaciones intrínsecas y extrínsecas a la esfera de riesgo de las partes ${ }^{(10)}$.

Dentro del primer grupo, es posible ubicar a las imperfecciones e inconsistencias en los planos, especificaciones técnicas, estudios y otros documentos contractuales, eventos de riesgo a cargo del comitente, del contratista o de ambos (Podetti 2004, $323)^{(11)}$, incluyendo de quienes se valieron para elaborar los referidos instrumentos. Entre las razones más frecuentes de estas situaciones podríamos mencionar las siguientes:

- los errores imputables a los profesionales involucrados en el proyecto (cliente, comitente, diseñador y contratista);

- el tiempo insuficiente del que disponen los profesionales para la elaboración de los estudios técnicos y el diseño;

- la asunción de tareas ajenas a su expertise por parte de los profesionales vinculados a los diversos partícipes;

- la generación de información más exacta sobre el proyecto en una oportunidad posterior a la elaboración de los documentos contractuales;
- la falta de coordinación entre los profesionales involucrados; $y$,

la información inadecuada proporcionada por los partícipes del proyecto.También son causas intrínsecas de variaciones las siguientes:

- la falsedad e inobservancia de declaraciones y garantías, así como el incumplimiento de obligaciones y cargas de las partes;

- la discontinuidad de los documentos contractuales iniciales debida a la demora en el proceso de negociación, frecuentemente influenciado por razones políticas o burocráticas;

- las necesidades de financiamiento para la continuidad de proyectos, la cual acarrea la necesidad de celebrar adendas de bancabilidad;

- la necesidad de optimización o ajuste del diseño en base a información generada u obtenida en el desarrollo del proyecto;

- los cambios en la apreciación estética y de conveniencia del comitente o del cliente;

- las vicisitudes legales y/o físicas previsibles;

- la demora en la emisión de licencias y permisos ambientales, regulatorios, arqueológicos asociados al sitio;

- la divergencia entre las condiciones del sitio esperadas y aquellas reales;

- las dificultades asociadas a la entrega área del emplazamiento y de sus accesos, a la secuencia de operaciones y a las restricciones en el tiempo de trabajo; $y$, la corrupción.

En segundo lugar, constituyen causas extrínsecas de variaciones aquellas ajenas a la esfera de riesgo a cargo de los contratantes, en tanto frecuentemente resultan imprevisibles. Para efectos de semejante calificación no consideramos determinante si los eventos que generan la necesidad de variaciones resultan

Durante los tres (03) primeros años contados desde la fecha de suscripción del Contrato, no pueden suscribirse modificaciones contractuales a los Contratos de APP, salvo que se trate:

1. La corrección de errores materiales.

2. Hechos sobrevinientes a la adjudicación de la Buena Pro que generan modificaciones imprescindibles para la ejecución del proyecto. 3. La precisión de aspectos operativos que impidan la ejecución del Contrato.

4. El restablecimiento del equilibrio económico financiero, siempre y cuando resulte estrictamente de la aplicación del Contrato suscrito, de acuerdo a lo dispuesto en el artículo 37".

(10) Las clasificaciones de los estudiosos son bastante heterogéneas. Así, solo a manera de ejemplo, hay quien ha distinguido entre variaciones beneficiosas y perjudiciales. Las primeras ayudarían a mejorar la calidad, reducir el costo, programa o grado de dificultad en el proyecto. Las segundas, en cambio, serían aquellas que reducen el valor del comitente o presentan un impacto negativo en el proyecto (Arain $\&$ Low 2003, 497-498). Otra opinión distingue entre variaciones necesarias y por conveniencia (Sergeant \& Wieliczko 2014, 17). 
sobrevinientes o de cognoscibilidad sobreviniente a las partes.

Entre las principales causas extrínsecas tenemos las siguientes:

- cambios en las condiciones físicas, tales como eventos de caso fortuito o fuerza mayor o los eventos geológicos extraordinarios;

- razones sociales, comunitarias y ambientales;

- cambios normativos y políticos;

- la obsolescencia de ciertos componentes o de ciertos métodos constructivos; $y$,

- los cambios en las condiciones de mercado (que podrían repercutir en los parámetros del proyecto).

Es importante advertir que la mencionada clasificación debe ser tomada como referencial e ilustrativa, en tanto las causas incluidas podrían desplazarse de una categoría a la otra en función a la distribución de riesgos y al nivel de previsión que, en el caso concreto, se hubiese derivado del contrato y de las circunstancias concurrentes.

\section{Las variaciones en los modelos comparados}

\subsection{Las variaciones en los estatutos internacionales de cláusulas estandarizadas}

A diferencia de la mayoría de las categorías lógicas existentes en el Civil Law, los principales Códigos europeo-continentales carecen no solo de un tratamiento orgánico para las variaciones en el marco de contratos de construcción, sino incluso de una definición para el fenómeno. No obstante, ciertos estatutos estandarizados internacionales podrían otorgarnos ciertas luces sobre la delimitación conceptual la categoría objeto de análisis.

En primer lugar, cabe traer a colación las disposiciones pertinentes de las Conditions of Contract for Construction (en adelante, el "Red Book"(12)), estatuto elaborado por la International Federation of Consulting Engineers (FIDIC) dedicado a los contratos de construcción con ingeniería diseñada por el comitente. La mencionada compilación se refiere a las variaciones como "cualquier cambio a los Trabajos, instruido como una variación según la Cláusula 13 (Variaciones y Ajustes)"(13).

Según la lógica del aludido estatuto, el término Trabajos ${ }^{(14)}$ engloba tanto a los Trabajos Permanentes como a los Trabajos
Temporales, siendo estos últimos aquellos (distintos a Equipamiento del Contratista) requeridos en el Sitio para la ejecución de los Trabajos Permanentes ${ }^{(15)}$. De este modo, la noción de variaciones propuesta por FIDIC no recae necesariamente en los componentes de la obra física, sino que engloba también cambios en Trabajos que no formarán parte del resultado final debido por el Contratista.

El Red Book complementa la definición formal ahora analizada con una enumeración de potenciales casos concretos (cláusula 13.1). Así, dispone que las variaciones pueden contener:

a) cambios a las cantidades de cualquier partida de trabajo incluida en el Contrato (sin embargo, tales cambios no necesariamente constituyen una Variación),

b) cambios a la calidad y otras características de cualquier partida de trabajo,cambios a los niveles, posiciones y/o dimensiones de cualquier parte de los Trabajos,

c) reducción de cualquier trabajo, si no es para que sea ejecutado por otros, sin el acuerdo de las Partes

d) cualquier trabajo adicional, Planta, Materiales o servicios necesarios para los Trabajos Permanentes, incluyendo cualquier Prueba de Culminación que esté relacionada, perforaciones y cualquier otro trabajo de exploración o de prueba, o

e) cambios a la secuencia u oportunidad de ejecución de los Trabajos.

Fuera de esta nómina, la cláusula 4.6 disciplina como una variación a la actividad de cooperación del Contratista con el personal del Propietario, con otros contratistas o con autoridades públicas cuando semejante cooperación hubiese sido ordenada por el comitente ante eventos Imprevisibles ( $y$, por ende, ajenos a la esfera de riesgo del Contratista).

(11) Según el autor, las alteraciones en la conducta prometida pueden dividirse en aquellas que son imputables a las partes y aquellas que no lo son. Según este parecer, en el primer escenario nos encontraremos fuera del ámbito de los cambios del contrato, y más bien en el cambio de los riesgos, responsabilidades y garantías. De este modo, solo cuando la modificación de la conducta programada se produce como consecuencia de un hecho exterior a la voluntad y diligencia de las partes enfrentaríamos un verdadero cambio en el contrato. Concordamos solo parcialmente con semejante delimitación, pues entendemos que podrían existir verdaderas variaciones que hallen su origen en eventos imputables tanto al propietario como al contratista.

(12) Hemos tenido a la vista la edición del Red Book 2017. Todas las ediciones de los libros FIDIC pueden ser obtenidas en: http://fidic.org/.

(13) Red Book de FIDIC, Cláusula 1.1.86.

(14) Cabe aclarar que las mayúsculas empleadas replican su utilización en los cuerpos normativos internacionales, al tratarse de términos específicamente definidos por aquellos.

(15) Red Book de FIDIC, Cláusula 1.1.80. 
La definición del Red Book, que aparenta ser flexible, dejaría fuera a los cambios en (i) las tareas administrativas de los contratistas, tales como la remisión de reportes periódicos (Lofthouse 2011, 2 y $4^{(16)}$ ), que configuran actividades eventualmente necesarias para llevar a cabo los trabajos; y, (ii) a las tareas de dirección organizativa interna del referido deudor. En cuanto al aspecto subjetivo de los cambios, la cláusula 13.1 del Red Book faculta al Ingeniero a iniciar el procedimiento de introducción de una variación en cualquier momento previo a la emisión del Certificado de Culminación de los Trabajos ${ }^{(17)}$.

Bastante coincidente con las reglas del Red Book parece ser la regulación de las ICC Infrastructure Conditions of Contract Measurement Version (18) (en adelante, las "ICC Conditions"). El referido corpus disciplina al fenómeno abordado en los siguientes términos:

ICC Conditions. Cláusula 51.-

“(...) variaciones pueden incluir adicionales, reducciones, sustituciones, modificaciones, cambios en la calidad, forma, carácter, clase, posición, dimensión, nivel o alineamiento y cambios en la secuencia, método o ritmo constructivo requerido por el Contrato y pueden ser ordenadas durante el Período de Remediación de Defectos."

Una definición semejante puede ser hallada también en las Conditions of contracts and forms of tender, agreement and bond for use in connection with works of civil engineering construction, publicadas por la Institution of Engineers of Ireland ${ }^{(19)}$ (en adelante, las "IEI Conditions"). En efecto, la cláusula 51 del mencionado estatuto establece lo siguiente sobre el tema que nos ocupa:

IEI Conditions. Cláusula 51.

"1) Modificaciones, adicionales o reducciones.- El Ingeniero ordenará cualquier variación a cualquier parte de los Trabajos que pueda, en su opinión, ser necesaria para la culminación de los Trabajos y tendrá el poder de ordenar cualquier otra variación que, por cualquier otra razón, pueda en su opinión ser deseable para la idónea culminación y funcionamiento de los Trabajos. Tales variaciones pueden incluir adicionales, reducciones, sustituciones, modificaciones, cambios en la calidad, forma, carácter, clase, posición, dimensión, nivel o alineamiento y cambios en la secuencia, método o ritmo constructivo especificado (de ser el caso) (...)".
Ahora bien, resulta interesante apreciar que el cuerpo normativo apenas explicitado dispone que una variación podría configurarse como una obligación (cuando sea necesaria para la culminación de los Trabajos) o bien, alternativamente, como un derecho asociado a la figura del Ingeniero (cuando sea deseable para la idónea culminación y funcionamiento de los Trabajos).

Mención aparte amerita el tratamiento de las variaciones conferido en el Agreement and Schedule of Conditions of Building Contract, elaboradas por el Royal Institute of the Architects of Ireland, en consenso con la Construction Industry Federation y por la Society of Chartered Surveyors (en adelante, las "RIAI Conditions"(20)).

La cláusula 2 del mencionado cuerpo normativo, referida al "Alcance Contractual", regula a la categoría que nos ocupa de la siguiente manera:

RIAI Conditions. Cláusula 2.-

"El Contratista llevará a cabo y completará los Trabajos de acuerdo a los Documentos del Contrato, a las instrucciones y a la satisfacción razonable del Arquitecto quien podrá, a su absoluta discreción y periódicamente, elaborar diseños, detalles $\mathrm{y} / \mathrm{o}$ instrucciones adicionales escritas $u$ orales (en adelante, 'Instrucciones de los Gerentes del Proyecto') con respecto a:

a) La modificación del diseño, calidad o cantidad de los Trabajos o la adición, omisión o sustitución de cualquier trabajo (en adelante, las 'Variaciones'); (...)"

Del artículo explicitado, se infiere que las RIAI Conditions conciben a una variación como la modificación del diseño, calidad o cantidad de los Trabajos o la adición, omisión o sustitución de cualquier trabajo ${ }^{(21)}$. Semejante alteración bien podría ser instruida a absoluta discreción por el Arquitecto.

(16) Cabe aclarar que el autor se refiere a la versión Red Book 1999 cuyo contenido, en este extremo, es sustancialmente idéntico a la revisada actualmente.

(17) Semejante procedimiento, detallado en la cláusula 13.3, será distinto según si las variaciones han sido emitidas mediante Instrucción o han sido solicitadas al contratista mediante Requerimiento de Propuesta.

(18) Hemos tenido a la vista la versión de las ICC Conditions 2011. El mencionado documento puede ser obtenido en: http://www.rics.org/ $\mathrm{pe} / \mathrm{shop} / \mathrm{contracts}$-detail/?ec $=18980$

(19) Hemos tenido a la vista la tercera edición de las IEI Conditions (1980), revisada y reimpresa en octubre de 1990 y en enero de 2002 . El mencionado documento puede ser obtenido en: https://www.thenbs.com/Publicationlndex/documents?Pub=IEI

La razón de haber considerado el referido cuerpo normativo radica en que los propios expertos en el sistema irlandés destacan que el uso de su versión posterior resulta escaso (Lyden, 2006, 1).

(20) Hemos tenido a la vista la edición de las RIAI Conditions correspondiente al 2011. El mencionado documento puede ser obtenido en: https://www.thenbs.com/PublicationIndex/documents?Pub=RIAI

(21) De otro lado, dicho estatuto asigna al Arquitecto un ius variandi que le faculta impartir instrucciones ( $\mathrm{y}$, dentro de ellas, incorporar variaciones) en el proyecto. Sin embargo, las RIAI Conditions le confieren, de manera explícita, discrecionalidad en el ejercicio de semejante poder. 
Finalmente, cabe anotar que el Delay and Disruption Protocol de la Society of Construction Law (22) (en adelante, el "Protocolo") contiene una noción un tanto distinta a aquellas anteriormente enunciadas, pues define a las variaciones como:

"Cualquier diferencia entre las circunstancias y/o contenido de los trabajos contractuales tal como se han llevado a cabo, en comparación con las circunstancias y/o contenido según el cual los trabajos se describen en los documentos contractuales como requeridos o como se esperaba que se hubiesen ejecutado. Un cambio o variación puede o generar un derecho de EOT (ampliación de plazo) y/o pago adicional" (El agregado entre paréntesis nos pertenece).

Creemos que la definición del Protocolo enfatiza exclusivamente uno de los componentes de la variación: la alteración del alcance de trabajos. Sin embargo, no explicita otro sumamente importante: el acto volitivo de los contratantes dirigido hacia la incorporación del cambio en el programa contractual prexistente.

A diferencia de ello, en general, los estatutos internacionales explicitados coinciden en definir a las variaciones como las alteraciones en sentido amplio del scope of works introducidas mediante un elemento volitivo de uno o varios partícipes del proyecto legitimados para tales efectos (principalmente, el ingeniero y el comitente). La categoría puede estar conformadas por adicionales, reducciones, sustituciones, modificaciones, cambios en la calidad, forma, carácter, clase, posición, dimensión, nivel o alineamiento de los trabajos, así como por las modificaciones en la secuencia, método o ritmo constructivo, cooperación y trabajos temporales ajenos a los originalmente convenidos.

\subsection{Las variaciones en el Common Law}

Resulta sintomático notar que importantes estudios doctrinarios germinados en el Common Law sobre el tema que nos convoca (Callahan 2005; Sergeant \& Wieliczko 2014) omiten dedicar capítulos exclusivos a la delimitación conceptual de las variaciones, prefiriendo ocuparse de algunos de los aspectos de la institución que juzgan problemáticos. A pesar de ello, es posible afirmar que grosso modo la literatura y jurisprudencia en dicho modelo jurídico sobre la materia resulta compatible con los desarrollos de los cuerpos normativos estandarizados.

Así, se ha constatado que una variación es toda modificación, adicional o reducción instruida por el propietario que no se encuentra en el alcance de trabajos original (Phillips, 1999, 58). Luego, se trata de un ente "distinto a lo que fue anticipado al momento de la firma del contrato, a su inicio o incluso mucho más adelante" (Lofthouse 2011, 1). En ese sentido, la definición es lo suficientemente amplia para ser aplicable tanto al contenido de los trabajos como a su método de realización (Hughes, Champion \& Murdoch 2015, 235).
Hay quien asevera que tales definiciones no constituyen un paso hacia adelante, pues no toman en cuenta el problema constituido por las responsabilidades de las partes (Lofthouse 2011, 1). Según esta posición, la cuestión de quién asume el costo de las variaciones dependería de quién asume el riesgo de su verificación.

Consideramos que esta acertada observación se encuentra asociada a la idea de pertenencia o no de una actividad al scope of works, lo cual es una genuina premisa para la existencia de una variación. Para el análisis de este punto, nos remitimos al numeral 5.2 del presente trabajo.

De manera un tanto más exhaustiva, una notable opinión define a la variación como aquella:

"alteración a los trabajos y materiales previamente descritos a ser ejecutados por el contratista, es decir a aquellos que figuran en los planos y han sido descritos en las especificaciones, o que se presentarán como trabajos indispensables, o necesarios trabajos contingentes incluidos en la obligación del contratista consistente culminar los mencionados trabajos necesarios, bajo el 'inclusive price principle'”. (Duncan Wallace 1995, 877).

El autor aclara que la categoría descrita no puede ubicarse dentro de los trabajos contratados, es decir, dentro de aquellas tareas que el contratista ya se encuentra obligado a realizar a cambio del precio. Como se aprecia, el parecer expuesto construye la definición de variación tomando como premisa la delimitación del terreno correspondiente a los trabajos contratados (para nosotros, sinónimo de alcance de trabajos o, por su nomenclatura en inglés, scope of works), los cuales, a su entender, se dividirían en por lo menos tres categorías (Duncan Wallace 1995, 497, 877, 883 y siguientes):

- Trabajos necesarios. Son aquellos descritos en los planos y en las especificaciones técnicas del contrato de construcción.

- Trabajos complementarios. Son aquellas actividades o procesos que, aunque no se encuentran expresamente descritos

(22) Hemos tenido a la vista la edición 2017 del Protocolo. El mencionado documento puede ser obtenido en: https://www.scl.org.uk/sites/ default/files/SCL_Delay_Protocol_2nd_Edition.pdf 
en los documentos contractuales, son indispensables o inevitablemente necesarios (bajo el inclusive price principle) para para culminación idónea de los trabajos necesarios.

- Trabajos contingentemente necesarios. Son trabajos no descritos en los planos y especificaciones técnicas pero que se hacen exigibles únicamente ante circunstancias y dificultades acontecidas en el desarrollo de la obra ${ }^{(23)}$.

Prosiguiendo con su discurso, el autor (Duncan Wallace 1995, 877-878) alude a lo que sería un segundo componente lógico del concepto que nos ocupa, pues entiende que el término variación denota una alteración en los trabajos contratados que ha sido debidamente autorizada o instruida por el propietario o su arquitecto/ingeniero, y cuyo costo es prima facie responsabilidad del propietario frente al contratista. De este modo, sin importar su naturaleza voluntaria o involuntaria, las variaciones no autorizadas por el propietario lejos de legitimar al contratista a obtener un suplemento de precio, usualmente configuran un incumplimiento contractual, cuyos daños generados deben ser en principio compensables ${ }^{(24)}$.

Ahondando en su entendimiento sobre las variaciones, el autor precisa que también pasarían a formar parte de dicho género las omisiones (entendidas como la reducción de trabajos contratados) y las alteraciones (que, a su juicio, involucran la combinación de una omisión con una adición que la reemplaza) (Duncan Wallace 1995, 877).

Aunque valiéndose de una terminología distinta, recientemente otro autor ha arribado a conclusiones bastante compatibles con la expuesta, en tanto concibe a las variaciones como:

"trabajos ejecutados por el contratista, u omitidos del alcance de trabajos, normalmente por la dirección expresa del administrador del contrato (actuando en representación del propietario) de conformidad con un poder contractual, donde los trabajos instruidos son diferentes a los que se encontraban dentro del alcance de trabajos original, o representa una omisión de trabajos que el contratista de otro modo hubiera debido ejecutar. Una variación también puede ocurrir cuando un contratista es legítimamente dirigido a cambiar su forma de trabajos o re-secuenciar sus trabajos, lo cual puede ocurrir, por ejemplo, cuando un contratista es instruido a ejecutar sus trabajos de manera diferente a lo que se indica en el work method statement que forma parte del contrato. Una variación también puede surgir cuando un contratista legítimamente instruido a suspender sus trabajos por un período de tiempo. Las circunstancias en las que una variación puede ser instruida son diversas" (Bailey 2016, 346).
En síntesis, el formante doctrinario del Common Law reconoce la misma dualidad de componentes lógicos de las variaciones presente en los cuerpos normativos estandarizados: su ajenidad a los trabajos contratados y su incorporación a estos últimos mediante el procedimiento regular, que normalmente involucra una instrucción del comitente o del ingeniero.

\subsection{Las variaciones en el Civil Law}

La delimitación conceptual que nos convoca no ha concitado significativamente la atención de los estudiosos pertenecientes al modelo del Civil Law. Empero, de manera general, hay quien ha sostenido que los cambios son aquellas modificaciones del contrato de construcción que impactan en su elemento objetivo (Horgué, 1997, 39). A ello se ha añadido que la noción analizada se desenvuelve dentro de dos tipos de límites, los externos y los internos (Ugas 2011, 377), conforme se desarrollará en el numeral 5.2.1.2. del presente trabajo.

En el ámbito de las codificaciones tradicionales, el Código Civil italiano se refiere a las variaciones en las modalidades convenidas de la obra del siguiente modo:

Código Civil italiano. Artículo 1659 (variaciones consensuales del proyecto).-

El contratista no puede aportar variaciones a las modalidades convenidas de la obra si el comitente no las ha autorizado.

La autorización se debe probar por escrito.

Aun cuando las modificaciones han sido autorizadas, el contratista, si el precio de la obra total ha sido determinado globalmente, no tienen derecho a compensación por las variaciones y por los trabajos extra, salvo pacto en contrario.

Rubino y ludica destacan las diferencias existentes entre el precepto transcrito ${ }^{(25)}$ y su similar del Código Civil de 1865, el cual se refería a variaciones en el diseño establecido. Según los autores, el término empleado por el legislador de 1942 es idóneo en tanto resulta

(23) Vendrían a ser ejemplos de esta categoría la reposición de equipos instalados y hurtados durante el proceso de construcción, la cobertura de equipos instalados para evitar su deterioro ante las lluvias o la remediación de defectos.

(24) Sin embargo, el autor (Duncan Wallace 1995, 878) reconoce que en ciertas situaciones la culminación de las obligaciones contractuales podría requerir inevitablemente que el contratista realice ciertas alteraciones respecto a los trabajos contratados. Si bien se trataría de escenarios donde técnicamente se apreciaría un incumplimiento del contrato que únicamente generaría daños nominales, no constituiría un supuesto de variación.

(25) Los artículos 1660 y 1661 del Código Civil italiano hacen referencia a "variaciones al proyecto", término que, según los autores, debe ser entendido en sentido amplio, como sinónimo de "modalidades convenidas" (Rubino \& ludica 1992, 234). 
lo suficientemente amplio como para englobar a los cambios en el proyecto (entendido en sentido técnico) y a las modificaciones a las modalidades ajenas al proyecto stricto sensu, pero que se encuentran en el contrato o en anexos específicos (1992, 234-235).

En esta línea, los autores destacan acertadamente que las variaciones pueden involucrar:

"no solo la consistencia objetiva de la obra, esto es, la forma, la estructura, las dimensiones y el funcionamiento de esta, sino también aquellas modalidades de ejecución que han sido determinadas en el contrato, como por ejemplo los procedimientos constructivos, los plazos y el lugar, y en general cualquier cláusula contractual que involucre la ejecución de la obra" (Rubino \& ludica 1992, 235).

Otro comentarista del artículo 1659 del Codice Civile, afirma que la variación, que repercute en el objeto del contrato de obra, debe ser entendida como:

"la modificación en la obra contratada, que no forme parte del natural y normal proceso de culminación de la obra misma y que no haya sido prevista en sede de estipulación del contrato de obra, pero respecto a la cual se verifique la necesidad, la utilidad o la oportunidad tras haberse celebrado el contrato, antes que los trabajos hayan sido terminados y la obra haya sido aceptada sin reservas por el contratante" (Musolino 2011, 57)
Continuando en el ámbito de la codificación, cabe mencionar que importancia actual de las variaciones ha sido tal que el fenómeno ha abierto su camino (a través de una muy reciente modificatoria ${ }^{(26)}$ ) en el Código Civil alemán, el cual define a la mencionada categoría como los cambios en el resultado de la obra acordado o aquel que es necesario para lograr el resultado de la obra acordado(27)(28).

Por otra parte, algunos autores latinoamericanos han acotado el terreno de las variaciones a aquellos:

"cambios en la obra o en los trabajos necesarios para llevarla a cabo o en las condiciones en que se ejecuta el contrato, que implican una alteración cuya naturaleza modifica de hecho el contrato y exigen, por tanto, ser incorporados por las partes o por un tercero, en defecto del acuerdo entre ellas, al instrumento contractual" (Podetti 2004, 324).

Conforme a este parecer, los cambios pueden reunirse en tres grandes grupos (Podetti 2004, 324):

- Cambios en el objeto, esto es, modificaciones de cualquier naturaleza de

(26) Esta última introduce un tratamiento específico a la obra constructiva: Código Civil alemán. Parágrafo § 650a. "Contrato de Construcción.-

1. Un contrato de construcción es un contrato para la fabricación, restauración, demolición o remodelación de una edificación, sus áreas exteriores o una parte de estas. Para el contrato de construcción, serán de aplicación las disposiciones siguientes de este capítulo. Un contrato para el mantenimiento de una edificación es un contrato de construcción cuando la obra es esencial para la construcción o la permanencia del uso previsto".

(27) Código Civil alemán. Parágrafo § 650b. "Modificación del contrato; Derecho de instrucción del dueño de la obra.-

(1) Si el dueño de la obra solicita

1. un cambio en el resultado de obra acordado ( $\$ 631$, párrafo 2$)$ o

2. un cambio que es necesario para lograr el resultado de la obra acordado, las partes contratantes acordarán el cambio y el aumento o reducción de la remuneración que se pagará como resultado del cambio. El empresario está obligado a presentar una oferta sobre la remuneración adicional o su reducción, sin embargo, en el caso de un cambio según el parágrafo 1 numeral 1 solo estará obligado si para él la ejecución del cambio es razonable. Si el empresario, haciendo un análisis interno, declara no estar en capacidad de cumplir la solicitud del parágrafo 1 numeral 1 para hacer el cambio, tiene ella la carga de la prueba. Si el dueño de la obra asumió la responsabilidad de proyectar la construcción de la obra o las áreas exteriores, el empresario sólo estará obligado a presentar una oferta sobre el aumento o reducción de la remuneración, si el dueño de la obra cuenta con la planificación requerida para el cambio y la ha puesto a disposición del empresario. Si el dueño de la obra solicita un cambio por el cual el empresario no tiene derecho a un suplemento de remuneración según el artículo 650 c parágrafo 1, oración 2, las partes solo pueden aspirar a un acuerdo sobre el cambio. La oración 2 no es de aplicación en este caso.

(2) Si las partes no llegan a ningún acuerdo dentro de los 30 días posteriores a la solicitud de cambio conforme al parágrafo 1, el dueño de la obra puede ordenar el cambio por escrito. El empresario está obligado a cumplir con la orden del dueño de la obra, solo si la ejecución es razonable para él. En consecuencia, es de aplicación el parágrafo 1, oración 3".

(28) Como se aprecia, la regulación alemana se centra en el procedimiento de introducción de un cambio y en los derechos de las partes ante tal constatación antes que en la noción que nos compete:

Código Civil alemán. Parágrafo §650c. "Ajuste de la remuneración en caso de instrucciones de acuerdo con el § $650 \mathrm{~b}$, párrafo 2.

(1) El importe de la remuneración por el mayor o menor costo del trabajo como resultado de una instrucción del dueño de la obra se regula de acuerdo con la sección 650 b parágrafo 2. La remuneración ajustada es la calculada en base a los costos actuales requeridos más el recargo apropiado por los mayores gastos generales, riesgo y utilidades. Si el empresario también tenía el deber de proyectar la edificación o sus áreas exteriores, esto será regulado dentro de lo dispuesto en el caso de la sección $650 \mathrm{~b}$ párrafo 1 parte 1 número 2 no teniendo derecho a reclamar remuneración por un mayor esfuerzo.

(2) Para calcular la remuneración de la modificación, el empresario puede utilizar la cuantificación original estimada según lo acordado. Se asume que el cálculo correspondiente al parágrafo 1 se realiza con base al cálculo original. (...)". 
la obra proyectada o prevista en el contrato. Según el autor (2004, 325), esta subcategoría se subdivide en dos grupos:

a) cambios no imprescindibles para alcanzar el objeto (comúnmente denominados adicionales, en tanto se realizan fuera de las previsiones del contrato); y,

b) cambios imprescindibles para alcanzar dicho objeto, los mismos que, a su vez, podrían ser previsibles e imprevisibles.

- Cambios en las condiciones externas del contrato, como serían las condiciones de mercado, de la naturaleza, del emplazamiento de la obra y los descubrimientos científicos o tecnológicos.

- Manifestación de circunstancias prexistentes al contrato, pero que solo pudieron ser conocidas después. Por ejemplo, vicios o características del suelo, presencia de objetos no detectados en el sitio de la obra, errores o defectos en la ingeniería.

La definición explicitada parece incluir en el mismo género tanto a las genuinas variaciones como a las circunstancias que determinan su surgimiento. Sin embargo, parece ser que la relación lógica causa-efecto existente entre ambas entidades aconseja su separación.

Según otra posición adscrita al modelo latinoamericano, lo que usualmente se denomina variaciones de obras sería una categoría conformada tanto por obras extraordinarias como por trabajos adicionales, en el sentido que son actividades que no estaban contempladas en los contratos inicialmente pactados (Molina \& Ríos 2016, 138).

Conforme a este punto de vista, una obra extraordinaria sería una modificación del proyecto original contratado, es decir, una obra material que no estuvo contemplada en aquel (situación que justificaría el calificativo de extraordinaria). En cambio, un trabajo adicional "consistirá en una actividad que sí estuvo contemplada en el proyecto original, pero en un volumen o cantidad inferior al contratado, para aquellos casos o contratos en los que la cantidad o volumen de la correspondiente partida haya quedado fija y preestablecida" (Molina \& Ríos 2016, 138).

Finalmente, a diferencia de lo que ocurre con los modelos estandarizados y en el formante doctrinario y jurisprudencial del Common Law, los sistemas del Civil Law no parecen haber un mínimo común consolidado sobre la definición de las variaciones en los proyectos constructivos.

\section{Las variaciones en el sistema jurídico peruano}

Más de una disposición del Código Civil peruano contiene, como fragmento de su hipótesis de hecho, referencia explícita a las variaciones. A manera de ejemplo, repárese en los siguientes artículos pertenecientes al estatuto del contrato de obra:

Código Civil peruano. Artículo 1775.-

El contratista no puede introducir variaciones en las características convenidas de la obra sin aprobación escrita del comitente.

Código Civil peruano. Artículo 1776.-

El obligado a hacer una obra por ajuste alzado tiene derecho a compensación por las variaciones convenidas por escrito con el comitente, siempre que signifiquen mayor trabajo o aumento en el costo de la obra. El comitente, a su vez, tiene derecho al ajuste compensatorio en caso de que dichas variaciones signifiquen menor trabajo o disminución en el costo de la obra.

A pesar de la importancia de los efectos previstos en las citadas normas, la doctrina nacional que se ha abordado a este tipo transaccional, en vez de delimitar conceptualmente los cambios del contrato de obra, ha optado por presuponer dicha noción (Tovar \& Ferrero 2007, 159 y siguientes; AriasScheiber 2015, 528 y siguientes).

Ahora bien, no puede dejar de advertirse que, en el más amplio marco del ordenamiento jurídico peruano, la categoría objeto del presente trabajo se encuentra presente en el artículo 34 de la Ley de Contrataciones del Estado vigente (en adelante, la "Ley")(29). Las modificaciones al contrato (que no son otra cosa que variaciones consensuales) son disciplinadas de la siguiente forma por el aludido estatuto:

Ley de Contrataciones del Estado. Artículo 34. Modificaciones al contrato.-

(...)

34.10. Cuando no resulten aplicables los adicionales, reducciones y ampliaciones, las partes pueden acordar otras modificaciones al contrato siempre que las mismas deriven de hechos sobrevinientes a la presentación de ofertas que no sean imputables a alguna de las partes, permitan alcanzar su finalidad de manera oportuna y eficiente, y no cambien los elementos determinantes del objeto. Cuando la modificación implique el incremento del precio debe ser aprobada por el Titular de la Entidad (...).

(29) Aprobada mediante Ley 30225 y modificada mediante Decreto Legislativo 1444 
Como se aprecia, el evento detonante de la modificación en el caso narrado es el acuerdo de las partes (acto de autonomía privada). Sin embargo, existe una serie de limitaciones para la libertad de los involucrados en este ámbito, tales como el hecho de que los cambios

- no configuren adicionales, reducciones o ampliaciones;

- hallen su origen en hechos sobrevinientes a la presentación de ofertas;

- no sean imputables a alguna de las partes;

- permitan alcanzar la finalidad del contrato de manera oportuna y eficiente;

- no cambien los elementos determinantes del objeto del contrato; $y$,

- en caso impacten en el precio, los apruebe el titular de la entidad.

Por otra parte, la Ley dedica una regulación algo más detallada a las variaciones introducidas unilateralmente por la entidad (comitente):

Ley de Contrataciones del Estado. Artículo 34. Modificaciones al contrato.-

(...)

34.2. El contrato puede ser modificado en los siguientes supuestos: i) ejecución de prestaciones adicionales, ii) reducción de prestaciones, iii) autorización de ampliaciones de plazo, y (iv) otros contemplados en la Ley y el reglamento (...).

34.4. Tratándose de obras, las prestaciones adicionales pueden ser hasta por el quince por ciento $(15 \%)$ del monto total del contrato original, restándole los presupuestos deductivos vinculados. Para tal efecto, los pagos correspondientes son aprobados por el Titular de la Entidad (...).

El mencionado dispositivo se ocupa de las prestaciones adicionales y de la reducción de prestaciones, categorías que constituirían una típica manifestación del ius variandi de la entidad; en la cual, según una difundida opinión, sería propio de los contratos administrativos (Guzmán, 2015, 616 y 617; Linares, 2009, 180).

Ahora bien, se constata que no cualquier modificación al contrato de obra dará lugar a una prestación adicional o reducción. Para que concurra tal supuesto, la alteración deberá recaer sobre una actividad a cargo del contratista y su impacto en la remuneración deberá encontrarse dentro de cierto límite cuantitativo (15\%) respecto al monto contratado original. Empero, existen ciertos casos de excepción en los cuales los adicionales de obra podrán ser incluso mayores a $15 \%$ del precio contractual, como se apreciará a continuación:

Ley 30225. Ley de Contrataciones del Estado. Artículo 34. Modificaciones al contrato.-

\section{(...)}

34.5. En el supuesto de que resulte indispensable la realización de prestaciones adicionales de obra por deficiencias del expediente técnico o situaciones imprevisibles posteriores al perfeccionamiento del contrato o por causas no previsibles en el expediente técnico de obra y que no son responsabilidad del contratista, mayores a las establecidas en el párrafo precedente y hasta un máximo de cincuenta por ciento $(50 \%)$ del monto originalmente contratado, sin perjuicio de la responsabilidad que pueda corresponder al proyectista, el titular de la Entidad puede decidir autorizarlas, siempre que se cuente con los recursos necesarios.

Adicionalmente, para la ejecución y pago, debe contarse con la autorización previa de la Contraloría General de la República. En el caso de adicionales con carácter de emergencia dicha autorización se emite previa al pago (...).

El tratamiento que la Ley dedica al fenómeno analizado es aplicable exclusivamente a las prestaciones adicionales y reducciones, que son solo una especie del género variaciones, configurado en los modelos comparados. $Y$ es que, como se verá más adelante, podrían existir variaciones en el alcance de trabajos que no necesariamente se adscriban en alguna de tales categorías.

Por otro lado, nótese que los parámetros cuantitativos fijados por la Ley (incluyendo los supuestos de excepción) constituyen uno de los indicios a considerar para diferenciar el terreno donde pervive el contrato original de aquel otro donde la introducción del cambio genera un nuevo proyecto $y$, por ende, un nuevo contrato. Solo el primero de los supuestos corresponde a una prestación adicional (como especie de variación), en sentido técnico-jurídico.

Dicho de otra manera, si bien las citadas normas (incluyendo a la Ley) no lo señalan de forma expresa, toda prestación adicional que sobrepase los límites cuantitativos explicitados podría, dependiendo de las circunstancias, exorbitar también la noción de variación y pasar a constituir, en caso sea aceptado por el contratista, lo que Common Law denomina como cardinal change. Como se explicará más adelante, esta situación podría dar lugar a un nuevo contrato de obra.

La identificación de semejante situación reviste importancia, en tanto un cardinal change podría acarrear la necesidad de una convocatoria a un procedimiento de licitación 
distinto, con sanciones de diversa índole si no hubiese sido llevado a cabo. $Y$ ello sin perjuicio de la eventual nulidad del nuevo contrato cuya formación no se ha ajustado al procedimiento regular, en vista de que su función económica individual (causa concreta) sería contraria a las normas de orden público. Como se puede apreciar, se trataría a todas luces de una situación que reviste no escasa gravedad.

En síntesis, se aprecia que los formantes doctrinario, legislativo y jurisprudencial en el Perú han omitido casi por completo la configuración general de las variaciones. Como consecuencia, no existe claridad sobre los alcances de las normas que contienen a dicha noción como parte de su hipótesis de hecho.

\section{La noción de variaciones}

Llegado a este punto, resulta pertinente reconstruir la noción de variaciones del contrato de construcción que, a nuestro juicio, resulta idónea y compatible con nuestro sistema. Para tal efecto, tendremos en cuenta los aportes de los modelos comparados (incluyendo desde luego los estatutos estandarizados internacionales), aunque sin perder de vista su compatibilidad con el ordenamiento positivo.

\subsection{Género próximo}

De manera general, podemos decir que las variaciones son negocios jurídicos que modifican contratos de construcción válidos y eficaces. Como ocurre con este tipo de negocios ${ }^{(30)}$, la variación repercute en una relación jurídica preexistente, a la cual presupone.

Desde esta perspectiva, la categoría analizada en el presente trabajo pertenece al género próximo conformado por los negocios modificativos del contrato, también denominados negocios de segundo grado. Estos últimos pueden hallar su fuente en el consentimiento de las partes (contratos modificativos ${ }^{(31)}$ ) o en la manifestación de voluntad de una sola de ellas (en caso la ley lo permita o el pacto previo lo disponga).

Como derivación de lo mencionado, entre las nociones de variación y modificación del contrato de construcción existe una relación lógica género-especie. Mientras una variación necesariamente es el resultado de un negocio jurídico modificativo (unilateral o consensual) del acuerdo original, no todo negocio modificativo origina una variación ${ }^{(32)}$.
La utilidad práctica de comprender que las variaciones son un subconjunto de los negocios modificativos radica en la determinación de su tratamiento aplicable (requisitos de forma y fondo) para su existencia, validez y eficacia. Así, por ejemplo, no podría concebirse la variación vinculante de un contrato de construcción sin que se verifique manifestación de voluntad regular, cuando esta última haya sido obtenida mediante coerción física o cuando el representante del comitente que la celebró carecía de facultades suficientes.

Finalmente, en virtud del principio de calificación objetiva de los negocios jurídicos ${ }^{(33)}$, las variaciones no necesariamente deberán ser textualmente denominadas como tales para que se les atribuya su naturaleza y efectos que les son propios. Así, el comitente podría impartir una instrucción sobre algún aspecto del proyecto frente a la cual, en una etapa inicial, ninguna de las partes sepa a ciencia cierta si se corresponde o no con una variación ${ }^{(34)}$. Ante tal circunstancia, en un eventual escenario de solución de controversias, semejante instrucción deberá ser calificada objetivamente como variación solo si cumple con los componentes de la definición que expondremos a continuación.

\subsection{Diferencias específicas}

No todo cambio en el contrato de construcción da lugar a una variación en sentido técnico. Piénsese, por ejemplo, en la modificación del domicilio del comitente, en aquella que incorpora una cláusula resolutoria expresa o que elimina el mecanismo de solución de controversias preexistente.

En tales hipótesis nos encontramos indudablemente frente a alteraciones del contrato que hallan su origen en negocios jurídicos modificativos. Empero, a su vez, estaremos lejos de la noción técnica de variación ${ }^{(35)}$, toda vez que esta última repercute exclusivamente en el aspecto objetivo de

(30) Los cuales frecuentemente la doctrina legal contractual denomina negocios jurídicos de segundo grado.

(31) Código Civil peruano. Artículo $1351^{\circ}$.-

"El contrato es el acuerdo de dos o más partes para crear, regular, modificar o extinguir una relación jurídica patrimonial" (el resaltado es nuestro).

(32) En el siguiente apartado nos referiremos a las peculiaridades que diferencian a las variaciones respecto a su género próximo.

(33) Según el principio de calificación objetiva, el juez y árbitro no se encuentran vinculados a las calificaciones voluntarias efectuadas por sus autores de los negocios jurídicos sometidos a su competencia. Por el contrario, los mencionados funcionarios deberán atender a parámetros concretos para llevar a cabo el adecuado encuadramiento jurídico de los negocios, tales como el contenido del contrato, las prestaciones de las partes, la función económica y las características de la actividad de las partes.

(34) El esclarecimiento, para las partes, sobre si esta cuestión es una confirmación de un requerimiento contractual o una variación es considerado como una perenne dificultad. (Champion, 2007, 4).

(35) Engloba estas hipótesis en una segunda acepción amplia de variación Pennington (1997, 1). 
los contratos de obra preexistentes. En este orden de ideas, a continuación nos referiremos las diferencias conceptuales específicas entre el género próximo de los negocios modificativos y las variaciones (como especie del primero).

\subsubsection{Diferencias objetivas}

\subsubsection{Alteración del alcance de trabajos}

La principal diferencia específica entre una variación y un negocio que origina modificaciones contractuales (género próximo) radica en que solo la primera ocasiona una innovación o alteración en la línea base del alcance ${ }^{(36)}$ de trabajos (scope of works). En otras palabras, solo las variaciones, y no así cualquier otro negocio modificativo, introducen genuinos cambios en el scope original.

Lo mencionado revela la centralidad del alcance de trabajos en la indagación que nos compete. El razonamiento planteado justifica dedicar algunas líneas a precisar los contornos conceptuales de dicha categoría.

En líneas generales, puede aseverarse que el alcance de trabajos está conformado por todas aquellas prestaciones constructivas a cargo del contratista que (i) se encuentran directa o indirectamente relacionadas al producto global comprometido por aquel; (ii) por influencia contractual o legal se ubican dentro de la esfera de riesgos del referido deudor ${ }^{(37)}$ y (iii) se consideran remuneradas por el precio total.

Para detallar el contenido de alcance de trabajos, retomaremos a los valiosos aportes de Duncan Wallace, mencionados en el apartado anterior del presente trabajo. Como se recordará, según el autor, los trabajos contratados (para nosotros, sinónimo de alcance de trabajos $\left.{ }^{(38)}\right)$ pueden ser (i) trabajos necesarios, (ii) trabajos complementarios y (iii) trabajos contingentemente necesarios. Por nuestra parte, tomaremos como base las subcategorías identificadas por el autor, aunque con las precisiones y añadiduras que exponemos a continuación.

Son trabajos necesarios aquellas actividades constructivas descritas en los planos, especificaciones técnicas y otros documentos contractuales (entendiendo por estos aquellos instrumentos consensuados de los cuales emanan derechos y obligaciones para las partes). Así, por ejemplo, las actividades del contratista consideradas como tales en el cronograma formarán parte de sus trabajos necesarios.

El esclarecimiento de las tareas incluidas y excluidas de los trabajos necesarios se encuentra estrechamente asociado a la interpretación contractual, procedimiento destinado a fijar el significado jurídicamente vinculante de la declaración de las partes. $Y$ es que en la praxis las partes suelen dedicar no pocas cláusulas al scope of works. La tensión de intereses que justifica semejante regulación ad hoc ha sido descrita acertadamente de la siguiente forma:

La necesidad de esta cláusula es obvia. El comitente aspira a tanto trabajo como sea posible a cambio de la remuneración, mientras que el contratista aspira a hacer lo menos posible. Por ende, el comitente intenta definir el alcance tan amplio como sea posible ("todos los materiales de trabajo, servicios y otros trabajos necesarios para edificar la construcción"); en cambio, el contratista intenta definir tareas específicas ("instalar las cerchas de techo, tejas de madera y asfalto") considerando todo lo demás como un extra. (Sigfried citado por Callahan 2005, 25).

Ahora bien, la interpretación de la cláusula dedicada al alcance de trabajos a menudo resulta compleja por dos razones. Por un lado, porque suele estar en función a documentos técnicos y a factores ajenos al contenido del contrato, tal como sería la data extraída (o susceptible de ser extraída) del sitio, la cual podría condicionar el tipo de cimentación a emplearse. En segundo lugar, a causa de las definiciones imprecisas, ambiguas o innecesariamente generales empleadas por las partes. Ejemplo de ello serían los siguientes pactos: "la obra deberá incluir todo lo que fuese necesario para cumplir sus funciones" o "se consideran incluidos todos los elementos necesarios para alcanzar el resultado prometido" (Podetti 2004, 325; Franco 2015, 132).

Si bien la dilucidación del alcance es una situación usualmente problemática, para la jurisprudencia angloamericana es claro que no todo el contenido del scope of works puede estar previsto en los documentos técnicos y contractuales (especialmente cuando la obligación del contratista es llevar a cabo un trabajo integral). En otras palabras, resulta virtualmente imposible incorporar de forma expresa en tales documentos absolutamente todos ítems y actividades constructivas (Pennington 1997, 4) $)^{(39)}$.

(36) En el ámbito de la dirección de proyectos, línea base suele ser definida como la versión aprobada de un producto de trabajo (en este caso, el alcance a cargo del contratista), el cual solo puede alterarse mediante procedimientos formales de control de cambios. Una línea base es usualmente empleada como punto de comparación con los resultados reales sometidos a evaluación.

(37) En ese sentido, cuando se habla de alteración al alcance, en el fondo se quiere aludir a la introducción de actividades ajenas a la esfera de riesgo del contratista (esto es, actividades extra o no contratadas).

(38) Resulta pertinente la distinción, pues el autor adopta una noción bastante más amplia de dicho término.

(39) Como consecuencia, se ha concebido la existencia de una obligación general de trabajo en el contratista, la cual puede ser entendida como "la obligación de realizar aquel trabajo que no se describe específicamente en los documentos contractuales cuando dicho trabajo 
Es en tal contexto que se origina la noción de trabajos complementarios o -como preferimos denominarlos, por ser una terminología más ilustrativa- trabajos instrumentales. Estos últimos pueden ser definidos como aquel grupo de actividades que, si bien no se encuentran descritos en los documentos contractuales, resultan necesarios o subordinados a la realización idónea y segura de los trabajos necesarios ( $\mathrm{y}$, mediatamente, a la conclusión del proyecto).

Una tarea constructiva debe ser calificada como instrumental si es que, perteneciendo a la esfera de riesgos del contratista, resulta razonablemente comprendida en la ejecución segura y funcional de algún trabajo necesario. De este modo, sin la verificación de la tarea subordinada, la realización de la actividad principal sería fácticamente inviable, inoperativa o peligrosa.

Con la finalidad de evitar las ambigüedades, creemos que la relación de dependencia antes mencionada deberá ser apreciada bajo un estándar de normalidad práctica. En tal sentido, la pregunta a responder será la siguiente: ¿en una situación de normalidad la actividad constructiva " $A$ " resulta prácticamente necesaria para la realización idónea y segura del trabajo necesario "B"?

Si la respuesta fuese afirmativa, la actividad subordinada será un trabajo instrumental y, consecuentemente, formará parte del scope of works del contratista remunerado con el monto total del contrato. Como contrapartida, si la respuesta fuese negativa, el trabajo en cuestión permanecería fuera del alcance contratado y podría constituir una alteración que origine una variación.

A manera de ilustración, es posible afirmar que, aun cuando no hubiesen sido previstas explícitamente en los documentos contractuales las siguientes actividades deben ser calificadas como instrumentales:

- la remoción de arbustos (no prevista pero previsible) por parte de un contratista de obra civil que asumió, mediante una declaración, el riesgo de las condiciones físicas exteriores del sitio;

- la prestación del constructor consistente en construir el piso de una casa tras haber asumido el compromiso de edificar esta última como una obra integral (Sergeant \& Wieliczko 2014, 50); y,
- el montaje temporal de andamios del contratista encargado de efectuar recubrimientos de los muros de un hospital.

En tales casos, aun cuando los documentos contractuales hubiesen omitido hacer referencia explícita a la remoción de arbustos, construcción del piso y empleo de andamios, dichas prestaciones integrarán el alcance de sus respectivos contratos por las dos siguientes dos razones: (i) resultan necesarias para la realización idónea y segura de los trabajos posteriores ( $y$, en general, de los proyectos a los que pertenecen); y, (ii) pertenecen a la esfera de riesgos a cargo del contratista, al resultar tareas previsibles.

De otro lado, formarán parte del scope of works los trabajos contingentemente necesarios. Estos últimos se componen de actividades constructivas que se caracterizan por su eventualidad, esto es, cuya necesidad de ejecución resulta incierta, al depender de circunstancias sobrevinientes (o de cognoscibilidad sobreviniente) incorporadas en la esfera de riesgo del contratista. En caso la necesidad de realizar estas actividades se haga tangible, estas pasarán a ser exigibles ya sea por derivar de los documentos contractuales o por ser instrumentales a la ejecución de los trabajos necesarios y del proyecto.

Así, por ejemplo, serán trabajos contingentemente necesarios del contratista las siguientes tareas coyunturales:

- la protección especial de equipos instalados en el sitio a causa de lluvias ocasionales acontecidas en el curso de la obra;

- en el marco de un contrato llave en mano, la re-elaboración de un plano combinado defectuoso producto de la falta

es esencial para completar y cumplir con la obligación general" (Pennington, 1997, 4). De esta manera, la noción de alcance se ensancha para incluir aquellos riesgos asociados al proceso constructivo que, según el contrato, el contratista ha aceptado tomar (Sergeant \& Wieliczko 2014, 33).

Con ocasión al esclarecimiento de trabajos contratados, Ramsey \& Furst han planteado una idea bastante similar. Los autores destacan que si un contratista debe completar un trabajo integral (tal como una casa o una vía férrea del punto "A" al punto "B" a cambio de una suma alzada), las cortes inglesas suelen inferir la promesa del contratista de proveer "todo aquello indispensablemente necesario para completar el trabajo integral" (2014, s/p). Semejante principio, en jurisprudencia inglesa, englobaría las siguientes especies de trabajos: trabajos no declarados específicamente; trabajos no derivados de las cantidades entregadas al contratista para elaborar su oferta o cantidades erróneamente establecidas en los planos; trabajos imprevistos ocasionados por dificultades del terreno o del método propuesto para su ejecución; trabajos derivados del ejercicio legítimo (y no irrazonable), por parte del propietario, de los poderes legales existentes al momento de celebrar el contrato; y trabajos instruidos por el ingeniero, aunque únicamente si el contrato (i) no establece una específica metodología de ejecución de actividades para la culminación de los trabajos y (ii) contiene una cláusula según la cual aquellos deban realizarse bajo la dirección y a satisfacción del ingeniero. 
de coordinación entre las ingenierías correspondientes a dos sistemas manejados por subcontratistas distintos; $y$,

- la obligación de un contratista de implementar una mayor cantidad de cámaras de vigilancia respecto al número previsto referencialmente en la planilla de cantidades, si es que ello fuese necesario para garantizar la visibilidad de todo el tránsito de pasajeros (resultado que el contratista había garantizado contractualmente).

Como contrapartida, no serían trabajos contingentemente necesarios aquellos que encuentran su origen en un evento de responsabilidad del comitente. Tal sería el caso del almacenamiento de equipamiento especial (inicialmente imprevisto) cuya necesidad para el contratista se generó única y exclusivamente a causa de la falta de entrega de terrenos a cargo de su contraparte. En este escenario, el contratista tendrá derecho a obtener una variación del alcance, con el consiguiente impacto en su remuneración y, eventualmente, en el plazo ${ }^{(40)}$.

Fuera de los componentes del scope of works previamente desarrollados, creemos que el concepto de alcance de trabajos se complementa con aquellas actividades constructivas exigibles en virtud las fuentes de integración del contrato, siempre que estas se encuentren asociadas al producto de comprometido por el contratista. Denominaremos a estas actividades como trabajos heterónomos, en tanto su exigibilidad no deriva directamente del programa voluntariamente dispuesto por las partes, sino de fuentes reguladoras externas.

Dentro de este cuarto grupo de trabajos comprendidos en el alcance destacan las actividades que derivan de la legislación imperativa general y sectorial y, desde luego, aquellas emanadas de los usos y costumbres (es decir, de las buenas prácticas profesionales de la ingeniería y construcción) y de la buena fe objetiva. Se trata, indudablemente, de actividades de riesgo a cargo de contratista.

A manera de ilustración, serán actividades heterónomas aquellas que configuran la obligación del contratista consistente en entregar la obra al comitente en condiciones de limpieza y seguridad. Ello al margen de que la autonomía privada de las partes haya introducido dicho deber en los términos y condiciones acordados.

Sintetizando este punto, constituirá una alteración al scope of works que pueda dar lugar a una genuina variación aquella que, situándose fuera de la esfera de riesgos del contratista, no forme parte de los trabajos necesarios, instrumentales, contingentemente necesarios ni heterónomos.
Pasando a otro punto, es pertinente afirmar que las repercusiones en el alcance de trabajos ocasionadas por una variación admiten una gama bastante amplia de manifestaciones. En efecto, aquel fenómeno puede incidir en las cantidades, calidad, especificaciones, dimensiones, secuencia constructiva, modalidades de ejecución o métodos constructivos, trabajos temporales o permanentes, forma, carácter o posición del proyecto ${ }^{(41)} \mathrm{o}$ de sus características convenidas.

En esta línea, serán ejemplos concretos de cambios los negocios modificatorios mediante los cuales se produzca cualquiera de las siguientes innovaciones en la línea base del alcance:

- el incremento de las dimensiones de un muelle;

- la sustitución de un componente representativo de la lista de insumos a ser empleados en el asfaltado de una infraestructura vial;

- la ejecución de cierto frente empleando métodos mecánicos antes que mano de obra (como se convino originalmente);

- la aceleración de las pruebas de commissioning de una central hidroeléctrica con la finalidad de que el comitente pueda cumplir los plazos fijados por su cliente; o,

- el aplazamiento del inicio de los trabajos del subcontratista encargado de instalar cablevías, con la consiguiente necesidad de reorganizar su secuencia de actividades.

Es importante considerar que una modificación en el alcance capaz de provocar una variación no necesariamente implica trabajos físicos o corporales por parte del contratista, sino que bien podría suponer modificaciones en los intangibles, tales como servicios, tecnologías que conforman sistemas o subsistemas de la obra o la transferencia de derechos de propiedad intelectual. En otras palabras, la categoría que nos ocupa incidirá sobre los componentes que integran la obra constructiva, sean tangibles o intangibles.

(40) Alternativamente, el contratista podrá acceder a una compensación de daños y perjuicio bajo las reglas de la responsabilidad civil.

(41) Semejante amplitud podría ser perjudicial para el propietario por la amplia exposición a las consecuencias de las variaciones. Sin embargo, dicho riesgo puede ser mitigado mediante una adecuada redacción del contrato de construcción. Al respecto, refiriéndose a los trabajos temporales y métodos constructivos, Duncan Wallace $(1995,901)$ ha considerado que una redacción contractual óptima debe tomar en cuenta las siguientes consideraciones (i) asignación al contratista del riesgo de la elección de los referidos aspectos del alcance (aun cuando el propietario o supervisor los apruebe), (ii) asignación al propietario del poder de ordenar ajustes en los métodos constructivos o trabajos temporales antes situaciones específicas sin impacto en precio y tiempo; y, (iii) asignación al propietario de un amplio poder de introducir variaciones discrecionales. 
De otra parte, las alteraciones del scope of works suelen incidir en los trabajos permanentes. Sin embargo, bien podrían involucrar actividades meramente temporales. Esto último ocurrirá, por ejemplo, si para la construcción de un tren subterráneo el contratista debe ejecutar túneles de acceso adicionales (esto es, no previstos originalmente en el proyecto) con el objeto de permitir el ingreso de la maquinaria pesada. Dichos trabajos provisionales constituirían una variación aun cuando el túnel proyectado inicialmente termina siendo exactamente el mismo, es decir, a pesar de no haberse alterado el entregable final originalmente previsto.

Según una destacada opinión (con la que concordamos) forma parte del concepto objeto de análisis la aceleración, categoría que concurre:

"cuando un contratista invierte mayores recursos (como por ejemplo movilizar más personal directo e indirecto, incorporar más subcontratistas dividiendo el trabajo o movilizar más equipos) o tomar otras medidas originalmente no previstas (tales como que el personal trabaje horas extras, variar los turnos de trabajo o realizar trabajos en días no laborales) para ejecutar los trabajos más rápido de lo planificado"(...) (Franco 2015, 130).

Conforme a este parecer, como regla, resulta necesario aplicar a las aceleraciones los principios que rigen las variaciones. La razón de ello radica en que la primera hipótesis rompe con la cantidad de recursos presupuestados al momento de contratar y puede generar un desequilibrio económico-financiero en el contrato (Franco 2015, 130 y 133)(42)(43).

Apelando a otro criterio, una innovación en el scope susceptible de convertirse en una variación puede consistir en la remoción de una alternativa contractual otorgada por el comitente a su contraparte. Así, por ejemplo, si el contrato le permite al contratista a triturar y usar el material resultante de las excavaciones y demoliciones o, alternativamente, a importar el material adecuado para relleno en sus tareas constructivas, constituirá una variación aquella instrucción del comitente dirigida a que el contratista realice obligatoriamente la primera de las opciones descartando la otra (Ramsey \& Furst 2014, s/p).

5.2.1.2. Permanencia dentro del límite externo A fines de delimitar el terreno propio de las alteraciones en los trabajos contratados capaces de dar lugar a variaciones, un sector de la doctrina del Civil Law ha destacado acertadamente que aquellas se enmarcan dentro de dos límites: uno externo y el otro, interno (Ugas 2011, 377) ${ }^{(44)}$. Gráficamente, los mencionados límites pueden ser concebidos de la siguiente forma:

\section{Límite externo}

Alteración de la línea base del alcance apta para
constituir una variación

Límite interno

No darán lugar a variaciones, por sobrepasar el límite externo, aquellos cambios (normalmente instruidos por el comitente) que impactan tan material y significativamente en el alcance que desnaturalizan el proyecto, dando lugar a uno nuevo y, consecuentemente, a una novación objetiva de la relación contractual primitiva (Ugas 2011, 374; Musolino 2011, 64)(45).

En esta línea, se ha afirmado que la noción de obra nueva constituye un verdadero límite sustantivo para las variaciones (Horgué 1997, 138-142)(46)(47). Y es que las modificaciones descritas, independientemente de su impacto

(42) Contra: Molina \& Ríos (2016, 140 y 141) para quienes no se incluyen dentro de esta noción las modificaciones de la organización y logística del constructor producto de restricciones en el área o superficie disponible para ejecutar las tareas constructivas, en tanto no hay obras constructivas asociadas a ello y la actividad constructiva propiamente tal no ha variado. Por lo tanto, correspondería tratar a dichas situaciones como impedimentos, restricciones, hechos catalogados como incumplimientos del mandante o casos fortuitos, según el caso del que se trate. También en sentido crítico: Horgué $(1997,37)$ quien aduce que los poderes modificatorios que determinen la suspensión de los trabajos más que una modificación del objeto del contrato, en orden a la calidad o cantidad de las prestaciones en que éste consiste configuran una decisión que impide la ejecución del mismo. Como consecuencia, la reparación económica involucrada no podrá canalizarse mediante el ajuste de precio del contrato.

(43) Sobre el particular, ha señalado que los poderes unilaterales para introducir aceleraciones o adelantos en la fecha de culminación (es decir, para dar órdenes de aceleración) son virtualmente desconocidos. Ello se debe a que la fecha de culminación establecida en el contrato se presume planificada en base a una óptima fuerza industrial y laboral.

(44) En particular, la autora (interpretando el art. 1661 inc. 2 del Código Civil italiano) sostiene que "no podrían incluirse dentro del concepto de variaciones, aquellas que inciden 'notablemente' en la naturaleza de la obra, y tampoco -por razones de orden interpretativo- aquellas que constituyen un 'ordinario' desenvolvimiento de las actividades instrumentales de su realización”.

(45) En efecto, aquellas no suponen una específica e inequívoca voluntad de novar ni tampoco significativos elementos de innovación vinculados a la aludida voluntad.

(46) Cabe señalar, que la autora efectúa sus reflexiones con ocasión al ius variandi administrativo; sin embargo, consideramos que muchas de ellas resultan aplicables al ámbito privado habida cuenta de la naturaleza de la categoría. Estas últimas estarán presentes cuando se modifique la obra original, pero en modo alguno existirán cuando dicha obra quede desnaturalizada de manera tan significativa que ocasionen la configuración de un nuevo proyecto.

(47) Sobre el particular, el artículo 526-1 del Anteproyecto de Código Mercantil español determina que existirá una alteración sustancial de la obra "cuando las variaciones necesarias comporten un aumento o disminución que exceda la quinta parte del precio pactado o cuando impliquen una modificación significativa de la naturaleza de la obra o de su forma". 
cuantitativo o cualitativo, extralimitan materialmente el ámbito objetivo de la obra inicialmente concebida, superando toda previsión razonable de las partes al momento de contratar. Como consecuencia de ello, tales innovaciones generarán contratos de construcción nuevos y ajenos al original, al cual a menudo reemplazan ${ }^{(48)}$.

Ejemplos de modificaciones que sobrepasan el límite externo (y que, por ende, no dan lugar a una variación en sentido estricto) se encuentran constituidos por:

- la sustitución consensual de un puente a ser erigido sobre un río por un túnel que pasará debajo del mismo río; o,

- un contrato previsto para mejorar y acondicionar el asfalto de la carretera que se modifique para incluir un cambio en el trazo de la vía (Horgué 1997, 138-142).

Un razonamiento análogo al expuesto puede ser apreciado en ciertas voces del Common Law. Al respecto, con ocasión al conocido caso Thorn vs. London Corporation, Lord Cairns expresó las siguientes consideraciones (citadas por Sergeant \& Wieliczko 2014, 134):

O el trabajo adicional y modificado que se ha ocasionado es el tipo de trabajo adicional y modificado contemplado en el contrato o no lo es. Si se trata del tipo de trabajo adicional o modificado contemplado en el contrato, deberá ser remunerado, y lo será, de acuerdo con los precios regulados por el contrato. $\mathrm{Si}$, en cambio, se trata de un trabajo adicional o modificado, tan peculiar, tan inesperado y tan diferente de lo que cualquier persona habría estimado o calculado, no estaría en absoluto dentro del contrato; entonces, me parece, que (el contratista) dispondría de una de las dos siguientes alternativas; podría haber dicho: Me niego completamente a seguir adelante con el contrato -Non haec in foedera veni: Nunca pensé construir esta obra sobre esta nueva (...) base. O pudo haber dicho, continuaré con esto, pero no se trata de la clase de trabajo extra contemplado en el contrato, y si lo ejecuto, debo ser remunerado a quantum meruit por él. (El resaltado y el agregado entre corchetes es nuestro).

El caso narrado nos ilustra sobre lo que en el Common Law se conoce como la cardinal change doctrine. Esta corriente propugna la ajenidad al universo de los cambios o variaciones de aquellas modificaciones que sobrepasan materialmente los trabajos originalmente convenidos, al punto de ser ajenos a las previsiones razonables de las partes al momento de celebrar el contrato de construcción.

En esta línea, se ha aseverado lo siguiente:
Si los trabajos no pudieron haber estado en la consideración de las partes al momento de celebrar el contrato, quedarán fuera del alcance de la cláusula de variación. De ello fluye, entonces, que mientras menos específicos son los trabajos en la etapa de licitación, más amplio es el alcance de la variación (Andriaanse 2016, 200).

En síntesis, los cardinal changes importan alteraciones al scope of works que van más allá del elemento objetivo (Pennington 1997, 3) o ámbito del contrato original. Luego, tras la introducción de un cardinal change, el alcance no puede ser considerado como esencialmente el mismo que aquel originalmente convenido. $Y$ es que, como se ha mencionado, se trata de cambios que superan la magnitud de modificaciones previsibles de los contratantes al momento de vincularse, dando lugar a una nueva relación contractual que solo puede derivar del consentimiento de ambas partes (Powell 1995, 378)(49).

Un buen ejemplo de aplicación de la aludida doctrina se encuentra dado por la decisión de un comitente (aceptada tácitamente por el contratista) de modificar radicalmente (al punto de casi reconstruir) una obra de infraestructura vial afectada por un desastre natural. En cambio, por su carácter razonablemente previsible y por su vinculación al alcance original, no será un cardinal change la instrucción a un contratista electromecánico para realizar prestaciones extra (originalmente no contempladas) de pago de impuestos que permitan el desaduanaje de equipamientos que si bien fueron importados por el comitente, el contratista los requerirá indispensablemente para ejecutar sus obligaciones.

A diferencia de las variaciones, los cardinal changes otorgan al contratista los siguientes derechos (Pennington 1997, 3) $)^{(50)}$ :

- rechazar la ejecución de tales cambios, previo a su incorporación,

- en caso los hubiese aceptado voluntariamente, reabrir los precios fijados

(48) Probablemente este sea el razonamiento que subyace a cláusula 13 de las RAI Conditions, según la cual "ninguna Variación invalidará este Contrato".

(49) Para tal efecto, en ocasiones se ha considerado que al contrato primigenio como abandonado por las partes, siendo que los cambios darían lugar a un contrato completamente nuevo (Powell 1995, 386).

(50) Hay quien ha considerado que el contrato no puede establecer válidamente un poder unilateral de introducir cardinal changes en las obligaciones del contratista, por lo que aquellas no serían vinculantes para dicho contratante (Pennington 1997, 3). En nuestro sistema jurídico, dicha afirmación halla total sustento en el principio de fuerza vinculante y el blindaje que acarrea contra arrepentimientos y/o alteraciones unilaterales y discrecionales del programa consensuado. 
para los trabajos posteriores liquidándolos conforme al quantum meruit ${ }^{(51)} ; \mathrm{y}$,

- negar la aplicación de ciertas cláusulas del contrato original, tales como el pacto de formalidad convencional y aquellas asociadas a plazos perentorios para reclamos.

A fines de establecer cuándo un presunto cambio ha excedido el límite externo y se ha transformado un cardinal change debe tenerse en cuenta no solo su impacto aislado, sino también las consecuencias de una multiplicidad de modificaciones, aunque sean sucesivas y no coetáneas. Y es que la acumulación de aquellas podría generar en el contratista un impacto mayor a la sumatoria individualizada de cada cambio particular (Hanna \& Swanson 2007, 61 y siguientes).

Autores como Powell se han ocupado de reconocer los indicios configuradores de un cardinal change en contratos de construcción con entidades gubernamentales norteamericanas. En su opinión, tales indicios pueden ser agrupados en dos categorías: aquellos vinculados al número de cambios introducidos en los trabajos contratados y aquellos asociados al propósito de tales cambios (1995, 378 y siguientes).

En el primer grupo se encontrarían (i) el número excesivo de cambios (en especial, aquellos que modifican el project delivery system primigenio) y (ii) las modificaciones ajenas a la razonabilidad, según el tipo de proyecto que se desarrolle ${ }^{(52)}$ (Powell 1995, 380, 382-390). Conforme al segundo grupo de indicios, existirá un cardinal change si (i) una modificación altera el ámbito o el carácter del contrato ${ }^{(53)} \mathrm{O}$ (ii) se introduce un cambio fundamental o material respecto al originalmente negociado (Powell 1995, 393-394) $)^{(54)}$.

Finalmente, cabe poner de manifiesto que, en las jurisdicciones del Common Law, el nivel de éxito de reclamos de contratistas bajo la teoría descrita anteriormente no ha sido precisamente elevado. Sin perjuicio de ello, creemos que dicha situación no compromete la existencia de la categoría, sino que podría obedecer a su difícil configuración y a las falencias en la estrategia legal de los contratistas.

El que una modificación del contrato de construcción supere los límites externos no requiere inexorablemente de un proyecto nuevo que reemplace al original. En efecto, también constituirán variaciones que exorbitan el límite externo aquellas alteraciones del alcance que, por sus características peculiares, sin extinguir el contrato primitivo resultan completamente ajenas a la previsión de las partes al celebrar el contrato de construcción.
Otro autor ha hecho referencia al problema apenas abordado con ocasión a lo que denomina trabajos ajenos al contrato:

Los trabajos extra pueden ser aquellos contemplados en las cláusulas del contrato vinculadas a la introducción de adicionales [extras] o pueden ser tan peculiares y tan diferentes que se encuentren fuera del contrato. Puede tratarse de trabajos fuera del contrato si aquellos son ejecutados luego de la culminación de los trabajos originales o si no se encuentran dentro del ámbito de la cláusula de variación. Los trabajos extra ajenos al contrato no se encuentran gobernados por las cláusulas del contrato, y no necesitan ser ordenados por escrito. Dependiendo de las circunstancias, puede encontrarse una obligación de pagar por los trabajos ajenos al contrato a través de la remisión de un nuevo contrato o a los principios del enriquecimiento sin causa (Ramsey \& Furst 2014, s/p).

En el Civil Law, el correlato del fenómeno apenas aludido ha sido denominado como obras nuevas complementarias. Se trataría de prestaciones consensuadas que cuentan con las siguientes características (Horgué 1997, 100-102):

- cuentan con individualidad propia;

- cuentan con su respectivo proyecto, distinto al original, el cual no se ve modificado ni reemplazado;

- no menoscaban el proyecto original, sino que se encuentran dirigidas a complementarlo y a facilitarlo (no siendo estrictamente indispensables para su culminación); y,

- los trabajos que las conforman son externos al contrato.

En esta línea, las obras nuevas complementarias no remplazan al proyecto original ni son indispensables para el cumplimiento de su finalidad. Por el contrario,

(51) La continuidad en la ejecución de trabajos de esta naturaleza constituiría en principio una aceptación tácita del contratista respecto al nuevo contrato. Así, en caso pretenda negar tal situación, el contratista tendría que haber manifestado su posición, por ejemplo, mediante un protesto y reserva de reclamos ulteriores. En cambio, si el sujeto siempre actuó como si estuviese vinculado al contrato y valorizando el work progress sobre la base de las tarifas inicialmente convenidas, sus probabilidades de éxito en un futuro reclamo podrían ser escasas.

(52) En esta línea de ideas, un proyecto fast-track permitiría la introducción de un volumen mucho mayor de cambios en la ingeniería sin ingresar al terreno del cardinal change.

(53) Ello ocurrirá, por ejemplo, en un cambio por el cual se triplique el volumen de tierra a ser removida por un pequeño subcontratista.

(54) En general, se considera que algunos de los elementos propios de un cardinal change pueden estar dados por (i) plazo ampliado para la culminación del contrato; (ii) incremento de costo en la materia prima; (iii) un requerimiento para el empleo de una materia primera distinta; (iv) distinto equipamiento o herramientas; (v) incrementos de requerimientos de personal más especializado; o (vi) incremento del porcentaje del tamaño del proyecto o (vii) incremento en el número de ítems a ser producidos (Powell 1995, 399). 
son prestaciones acordadas que se desenvuelven paralelamente a aquel.

A manera de ilustración, podemos mencionar el caso en que un contratista y su contraparte acuerden que el primero realizará diseñará e implementará una jaula metálica para aves -inicialmente no prevista- con ocasión a una obra de acondicionamiento de una casa.

\subsubsection{Superación del límite interno}

El límite interno es la línea divisoria que separa a las variaciones y del universo de los trabajos contratados. No configurarán variaciones (por no superar el límite interno y permanecer dentro del scope) aquellos ajustes menores, ordenados por el comitente, que canalizan el desarrollo ordinario las actividades propias de la ejecución de una obra. En este supuesto, nos encontraremos ante prestaciones de adaptación ordinaria e integración de la prestación debida por el contratista, es decir, en el ámbito de las simples instrucciones del comitente ${ }^{(55)}$.

En el ámbito del Construction Law se suele concebir a las instrucciones como aquellas comunicaciones de autoría del comitente o del supervisor a través del cual se imparte al contratista una orden de cumplimiento obligatorio relativa a la ejecución del contrato. Así, por ejemplo, una instrucción puede tener alguno de los siguientes fines (Duncan Wallace 1995, 502).

- la especificación o precisión de aspectos técnicos o contractuales genéricos, ya sea trabajos necesarios, instrumentales, circunstanciales;

- una solicitud de explicaciones;

- la confirmación de una solicitud;

- la aclaración derivada de eventuales errores, incertezas, inconsistencias o insuficiencias de los documentos contractuales;

- la identificación de trabajos defectuosos o potencialmente defectuosos;

- la solicitud de remediación de trabajos; y,

- únicamente en caso se hubiese pactado expresamente, interferencias con los métodos de trabajo del contratista.

Las nociones de instrucción y variación no son coincidentes, aunque ambas bien podrían concurrir en un mismo supuesto concreto. En efecto, si en base a una prerrogativa contractual el comitente (investido de facultades suficientes) ordena al contratista trabajos suficientemente determinados que extralimitan el alcance primigenio, dicho acto será una instrucción que, a la vez, contiene una variación (con los efectos asociados a estas últimas). Como contrapartida, las simples instrucciones que no incorporan un trabajo extra no son variaciones $\mathrm{y}$, por ende, no le permiten al contratista dirigir pretensiones remunerativas suplementarias ni de ampliación de plazo.

A continuación, mencionaremos un ejemplo concreto de simple instrucción ajena a la noción de variaciones. Un contrato de construcción prevé fechas estimadas para el inicio de las etapas y sub-etapas de trabajos. No obstante, anticipando incumplimientos de su cliente, el comitente incorpora un derecho contractual de, a su sola discreción, diferir el inicio de los trabajos en las fechas estimadas por un plazo de gracia de hasta sesenta días calendario, sin ningún tipo de repercusión económica (en remuneración y plazo) para aquel. En tal hipótesis, el ejercicio del poder del comitente dentro del período de gracia dará lugar a un impacto asumido por el contratista (y que debió ser tarifado al momento de cotizar). En el caso descrito, el desplazamiento de fechas será producto de una simple instrucción, en tanto se desenvolverá dentro del alcance contratado (en calidad de trabajos contingentemente necesarios).

Pasando a otro punto, también permanecerán dentro del límite interno (sin dar lugar a modificaciones en el scope potencialmente generadoras de variaciones ${ }^{(56)}$ ) las prestaciones de concreción (en ocasiones mal denominadas optimizaciones) del alcance a cargo de los contratistas. Como se sabe, dichas prestaciones canalizan la adaptación y desarrollo ordinario de la obra, cuya naturaleza especial requiere que el exacto cumplimiento del contrato que la enmarca termine de especificarse en un momento posterior a su celebración.

Al respecto, se ha destacado que en las obras complejas "por lo general el comitente da una serie de pautas o especificaciones técnicas generales; generalmente no muy detalladas y que dan cierto margen al contratista para que ejecute la obra dentro de este marco general" (Tovar \& Ferrero 2007, 160). Así, resulta inviable pretender que los documentos

(55) Estas últimas vendrían a caracterizarse por su previsibilidad genérica y por su levísima y marginal interferencia en el plano de la obra (Ugas, 2011, 377 - 379).

(56) En ese sentido, discrepamos con lo señalado por cierta opinión (Arias-Schreiber 2015, 529), la cual considera viable introducir una cláusula por la que se faculte al contratista a hacer las variaciones que estime conveniente. A nuestro juicio, a lo que en realidad parece querer aludir en autor es a las prestaciones de concreción que, como se mencionó, son distintas de las variaciones. Lo contrario, además de ser bastante peculiar en la industria, podría entrar en colisión con el principio contractual de fuerza vinculante, en tanto se trataría de una subordinación a la voluntad del contratista, carente de parámetros objetivos, de ciertas características del resultado esperado por el comitente. 
contractuales posean una rígida exhaustividad, razón por la cual aquello que no sea determinado deberá reconducirse a las "valoraciones de tipo medio y en último término a las previsiones generales de la conducta diligente como marco de la prestación del contrato" (Gudín 2011, 149).

En efecto, en tales circunstancias, el contratista cuenta con libertad para completar las características que faltan, "pero siempre dentro del espíritu de lo que buscaban las partes al momento de contratar y sin contradecir las especificaciones generales ya acordadas. El objetivo será que, además de desenvolverse dentro del marco pactado, la obra cumpla con las funciones y objetivos previstos en el contrato" (Tovar \& Ferrero 2007, 160).

Un ejemplo de prestaciones de concreción puede ser apreciado en las actividades de trazo o replanteo, asumidas por todo contratista civil que recibe planos elaborados por el comitente. En virtud de semejantes prestaciones, el constructor, a partir de estudios en campo, genera información adicional a la recibida con el propósito de fijar aspectos como la forma del perímetro de la obra o los ejes o los contornos donde se ubicará la cimentación. Desde luego, semejantes detalles no se encontraban presentes en los documentos contractuales, por lo que en cierto sentido se puede decir que el contratista complementa aquellos documentos ${ }^{(57)}$.

Finalmente, podría pensarse que la existencia de concreciones afecta la validez del contrato de construcción, a causa del riesgo de que el contratista fije discrecionalmente aspectos asociados al objeto negocial, lo cual podría entrar en colisión con el pacta sunt servanda. No obstante, el problema de validez es más aparente que real, dado que la elección del contratista es un procedimiento normal para finiquitar los detalles del alcance y no supone una innovación discrecional, sino una elección que se sujeta a parámetros y lineamientos objetivos, controlables ex post y en todo caso orientados por el deber de buena fe objetiva.

A manera de síntesis, se tiene que las prestaciones de concreción son aquellas actividades contratadas que, si bien no se encontraban especificadas a detalle en el proyecto, el contratista debe ejecutar dentro de parámetros o lineamientos (técnicos y/o contractuales). Así, en virtud a dichas prestaciones el alcance de trabajos del contratista no cambia, sino que se torna más definido (Bailey, 2016, 648). Las consecuencias de dicha constatación son que la especificación (i) forma parte de los trabajos contratados, (ii) no se encuentra sujeta a la aprobación del comitente y (iii) no dará lugar a reconocimiento de costos ni a ampliaciones de plazo a favor del contratista (Hernández 1999, 191) $^{(58)}$. Ambas consecuencias divergen diametralmente de la noción y consecuencias propias de las genuinas variaciones.

\subsubsection{Diferencias temporales}

En cuanto a su ámbito temporal, las variaciones tienen lugar en la etapa de ejecución del contrato, esto es, en el arco de tiempo que transcurre desde su celebración hasta la consumación de su vigencia.

De ello se desprende que, antes de la formación del contrato, los cambios que el titular del proyecto efectúe en los documentos técnicos (aun no contractuales) no son variaciones. Ello se debe a que en tal supuesto no existe aún un acuerdo contractual generador de obligaciones para las partes (Horgué 1997, 38) respecto a cuyo elemento objetivo (scope of works) operen las modificaciones. En tales casos nos encontraríamos frente a meros ajustes a los documentos técnicos precontractuales cuya versión final o actualizada será la única que se incorpore al contrato de construcción, en caso el contratista brinde su ulterior aceptación.

De otro lado, si la fuerza vinculante del contrato ha decaído (por consumación o alguna forma de extinción patológica), tampoco podría existir una variación, en tanto las variaciones presuponen un vínculo vigente entre las partes (Horgué 1997, 38).

\subsection{Delimitación negativa}

A continuación, procederemos a individualizar aquellas hipótesis que si bien escapan a la noción de variación, resultan especialmente complejas. Según consideramos, el deslinde conceptual de la categoría que nos ocupa respecto a nociones afines, enriquecerá el análisis desarrollado a este punto.

De entrada, debemos aclarar que variación no es sinónimo de desviación. Esta última implica un apartamiento del contratista (unilateral, no aceptado por el comitente) respecto a los documentos contractuales. En términos jurídicos, esta hipótesis da lugar a un incumplimiento relativo (cumplimiento parcial, tardío o defectuoso) del contratista.

Ante semejante escenario patológico, el comitente tendrá a su disposición una amplia gama de remedios aplicables frente a la violación del crédito contractual, tales como la responsabilidad por incumplimiento, penalidades, ejecución de garantías, resolución por incumplimiento, ejecución por tercero y similares, de ser el caso.

(57) El trazo o replanteo resulta absolutamente trascendental, en tanto la omisión o realización errónea de esta tarea podría generar defectos estructurales en la obra o inclusive su propia ruina.

(58) La autora se refiere, en particular, a los contratos de obra llave en mano. 
Si bien una desviación altera el scope of works, dicha consecuencia no deriva de ningún negocio jurídico modificativo del contrato de construcción. Así, la simple desviación no se encuentra aunada al otro componente lógico indispensable para la existencia de una variación: el negocio jurídico que introduce el cambio a la línea base del alcance.

Algunas voces incluyen dentro de la noción objeto de análisis a las variaciones menores, a las que a menudo definen como aquellas "relativas a detalles secundarios cuya necesidad y oportunidad se manifiesta solo en el curso de ejecución y que permanecen comprendidas dentro del orden normal de cosas". Por ende, semejantes ajustes no serían susceptibles de compensación adicional a la ya incluida en el precio (Perlingieri 1980, 992).

Al respecto creemos que, tal como han sido definidas, las variaciones menores no son genuinas variaciones al no alterar el alcance de trabajos. En efecto, parece adecuado calificar a las actividades no previstas por el contratista pero comprendidas dentro de un orden normal de cosas como trabajos instrumentales o, en otros casos, como trabajos contingentemente necesarios o heterónomos. En tales escenarios, el contratista actúa dentro de su scope of works remunerado con el precio total.

Tampoco constituirán variaciones las actividades de remediación de defectos a cargo del contratista. Si bien la exigibilidad de tales prestaciones es coyuntural (pues dependerá del eventual surgimiento de un vicio o defecto en los trabajos realizados), al constituir eventos de riesgo a cargo del contratista, indudablemente integrarán su alcance de los trabajos ${ }^{(59)}$. A mayor detalle, la remediación de defectos forma parte de los trabajos contingentemente necesarios.

Ahora bien, la excepción a esta regla estaría dada en aquellos supuestos en que la parte incumplidora ofrece una prestación que vaya más allá de aquella a la que estaba originalmente obligada (Steinberg 2017, 170). En este supuesto, bien podría existir una genuina variación del alcance, de constatarse el componente volitivo suficiente en el comitente.
Tampoco estaremos ante la categoría que nos ocupa cuando el contratista vea que los trabajos contratados se tornan más difíciles de ejecutar o más onerosos de lo previsto (Bailey 2016, 648). En tales escenarios, la noción de alea normal determina que el contratista deba superar tales dificultades absorbiendo el impacto en su presupuesto ( $y$, consiguientemente, reduciendo sus utilidades proyectadas), salvo el límite de excesiva onerosidad de la prestación. Sin embargo, ni siquiera en este caso nos encontraríamos dentro de la categoría objeto del presente trabajo, sino ante una mera modificación del equilibrio contractual.

Mucho mayor complejidad acarrea advertir que en ciertas ocasiones podríamos encontrarnos fuera de las variaciones aun cuando el contratista, con la anuencia del comitente, termine ejecutando cantidades de trabajo superiores a las estimadas en los documentos contractuales (principalmente, en la planilla de cantidades). Semejante divergencia cuantitativa puede deberse a que los volúmenes de items inicialmente descritos en los planos y especificaciones a menudo representan únicamente un cálculo grueso (meramente referencial( ${ }^{(60)}$ ) del trabajo real total, el cual, inicialmente determinable, a la postre se revela superior a las estimaciones ${ }^{(61)}$.

En múltiples ocasiones, los términos y condiciones del contrato asignan al contratista la probabilidad de quedar obligado a realizar mayor cantidad de obra (as-built) respecto a aquella as-planned ${ }^{(62)(63)}$. Bajo tal distribución, la fluctuación cuantitativa de volúmenes habrá

(59) Lo mencionado halla su base en el contenido del artículo 1782 del Código Civil, según el cual "El contratista está obligado a responder por las diversidades y los vicios de la obra" (...).

(60) Esta realidad es frecuente porque inicialmente la cantidad de trabajos es a menudo descrita con información limitada e insuficiente. Empero, posteriormente dicha cantidad se hace manifiesta su real dimensión.

En la hipótesis descrita, el componente cuantitativo del alcance (volumen final de metrados) es determinable, pues si bien inicialmente resulta incierto (solo estimado), se revelará con exactitud en un momento ulterior: cuando el contratista haya culminado de ejecutar la obra.

(61) Los riesgos que afronta el contratista ante semejante dislocación son dos:

(i) El quedar obligado a ejecutar volúmenes reales de trabajo superiores a los volúmenes as-planned. El impacto de la materialización de este riesgo es el costo de oportunidad de la realización de otros proyectos (por incremento del plazo del primer proyecto), así como la eventual insuficiencia de capacidad logística, financiera y técnica de cara a la ejecución de estas actividades ulteriores. Denominaremos a esta eventualidad el riesgo de la vinculación a las mayores cantidades. Como se aprecia, semejante riesgo resulta significativo y debe ser reflejado en el precio cotizado por el referido deudor.

(ii) El asumir el sobrecosto económico derivado de ejecutar las mayores cantidades, al no estar facultado para obtener mayor remuneración ni mayor plazo por su implementación. Denominaremos a este aspecto el riesgo económico de las mayores cantidades.

Para efectos del presente trabajo, interesa ahondar en el primero de los riesgos aislados (vinculación a las mayores cantidades), siendo la asignación del segundo propia de los sistemas de fijación de precio como la suma alzada o los precios unitarios.

Sin perjuicio de ello, con relación al segundo punto, diremos que la elección de la suma alzada como sistema de fijación de precios determina que el riesgo de la remuneración del mayor alcance derivado de la discrepancia entre el metrado estimado (as-planned) y el metrado real (as-built) sea asumido por el contratista. En efecto, si la primera medida es inferior a la segunda, la mayor cantidad de trabajo realizada por el contratista no será remunerado con un suplemento de precio, es decir, el impacto económico negativo del mayor volumen de trabajo será absorbido por el propio contratista (de ser el caso, reduciendo sus utilidades). 
sido una variable asumida (o que debió ser asumida) por el deudor desde la celebración del contrato. En el supuesto planteado, la cantidad real de trabajos requerida para el proyecto (aun cuando originalmente incierta) habrá formado parte del alcance remunerado.

Ante tales circunstancias, parece claro que si las cantidades reales se revelan mayores a aquellas as-planned (es decir, si se materializa el riesgo asumido), el contratista deberá implementar los referidos volúmenes de trabajos como parte de sus obligaciones y sin estar legitimado a obtener una variación remunerada. Dado que en esta hipótesis la realización de cantidades superiores a lo estimado no implicará nada más que la simple ejecución del alcance originalmente convenido. Así, al no haber alteración alguna de la línea base del alcance, la hipótesis descrita no originará una variación en el contrato de construcción.

Sin embargo, en la praxis suele ocurrir que el contratista se cuida de estipular de manera clara y precisa que son las cantidades de trabajo exactas contenidas en la planilla de cantidades (y no volúmenes superiores) las que constituirán el alcance remunerado con el precio. Semejante pacto asocia directamente los volúmenes de trabajo inicialmente calculados al alcance contratado, de manera que el cambio en el primero impactará necesariamente en el segundo.

En aquella hipótesis puntual, el riesgo de la existencia de volúmenes de trabajo superiores habrá sido contractualmente trasladado al propietario, quien de este modo habría concedido al contratista una suerte de garantía (warranty) de exactitud de los volúmenes as-planned. Por ende, al estar fuera del riesgo del contratista, el cambio de las cantidades será una alteración en alcance, de modo que el contratista tendrá expedito su derecho a acudir a la cláusula de cambios con las consecuencias que ello implique.

El siguiente punto de la delimitación negativa de las variaciones se encuentra orientado a distinguir entre estas últimas y las iniciativas (del comitente o contratista) destinadas alterar el scope of works. Entre las diferencias existentes, puede mencionarse que las segundas son meras propuestas (sean ofertas o invitaciones a ofrecer) y, por ende, no serán de obligatorio cumplimiento para la contraparte, ni modificarán el alcance contratado. Ello a menos que se trate de ofertas que hubiesen sido aprobadas expresa o tácitamente por la otra parte, momento en el cual habrán dejado de ser iniciativas para convertirse en genuinas variaciones. A mayor abundamiento, es posible observar que una iniciativa, en sí misma considerada, no dará lugar una variación, ni impactará inmediatamente en los trabajos contratados, sino que únicamente legitimará a la contraparte a seguir el procedimiento fijado para su introducción y, en caso este se lleve a término, constituirá un cambio.

llustraremos la noción e impacto de las iniciativas con un ejemplo. Cuando cierto proyecto ya se encontraba en marcha, y en ausencia de una cláusula de cambios, un contratista recibe planos revisados por el comitente. Como se sabe, a ese momento el contrato de construcción ya encontraba integrado con los documentos técnicos considerados al momento de su celebración (Spencer, 1955, 348). Dado que la comunicación con los planos actualizados no importa el ejercicio de un ius variandi (pues constituirá una mera propuesta), el contrato no se verá modificado por aquella. En cambio, una eventual variación del alcance dependerá de que el contratista acepte las modificaciones al proyecto sometidas a su consideración.

Pasando a otro punto, concebir a las variaciones como las alteraciones de los trabajos contratados implica excluir de aquel universo a los acuerdos destinados a remunerar una prestación ya asumida contractualmente por el contratista. Dicho de otra manera:

"si el contratista ya se encuentra vinculado, en la genuina construcción del contenido del contrato, a realizar ciertos trabajos a cambio del precio contractual, no existirá

Como contrapartida, el riesgo de la remuneración del mayor alcance se traslada al propietario en los proyectos a precios unitarios. Ello en la medida en que la mayor cantidad de trabajo ejecutado deberá ser correspondida con mayor remuneración, por encima del precio referencial inicialmente acordado. Evidentemente, la conclusión sería distinta si los mayores metrados se debieran a que ambas partes (o una de ellas) decidieron alterar los volúmenes originalmente estimados con sus manifestaciones de voluntad posteriores a la celebración del contrato.

(62) A mayor detalle, semejante asunción se manifestará cuando el comitente no haya asumido una garantía:

Cuando el comitente declara que las cantidades as-planned resultan meramente referenciales y susceptibles de fluctuación en la ejecución del proyecto. En este supuesto, el volumen real de actividades es un dato inicialmente ignorado por ambas partes, que solo se aclarará con el devenir de la obra.

Cuando el comitente no otorga al contratista una garantía (warranty) de exactitud cuantitativa que lo proteja ante la divergencia mencionada en el apartado anterior. Y es que, como regla, dicha garantía (warranty) no será implícita (Ramsey \& Furst 2014, s/p).

El autor distingue dos escenarios (Ramsey \& Furst 2014, s/p). El primero de ellos se presenta cuando los documentos que describen las cantidades son remitidos al contratista para permitirle cotizar y emitir propuesta económica. En este escenario, los referidos documentos no serán contractuales. En cambio, las cantidades sí serán documentos contractuales en caso se incluya redacciones como la siguiente: "de acuerdo a los planos y a las cantidades otorgadas por el arquitecto".

(63) Se tratará de trabajos contingentemente necesarios. 
consideration para ninguna promesa del propietario a pagarlos bajo la errónea impresión de que se trata de una variación" (Duncan Wallace 1995, 892 ${ }^{(64)}$ ).

En el Civil Law, la promesa del comitente consistente en pagar por una tarea ya incluida dentro del alcance de trabajos, configuraría un supuesto de imposibilidad jurídica del objeto. Ello equivaldría a pretender celebrar un negocio destinado a transferir la propiedad de un bien a favor de quien ya es su propietario. En tal escenario, el negocio jurídico constitutivo de la variación será nulo y, consiguientemente, la remuneración asociada a aquella no sería debida por el comitente ${ }^{(65)}$.

Continuando con la delimitación en negativo del terreno propio de los cambios, es necesario analizar la eventual pertenencia a dicha noción de aquellos trabajos no contratados cuya ejecución fue tolerada ${ }^{(66)}$ por el comitente.

Así, por ejemplo, imagínese que, en el progreso de los trabajos, un contratista viene empleando pernos de anclaje con características distintas a las contractuales (aunque resulten aptos para cumplir su función). Por su parte, el comitente, contando con conocimiento de tal situación, no objeta sino que tolera semejantes desviaciones. En tal escenario, no se aprecia en el comitente una manifestación de voluntad stricto sensu dirigida a modificar el scope of works introduciendo prestaciones de entrega de pernos de distinta calidad para el cumplimiento futuro del deudor. La patientia presentada por el propietario no resulta suficiente para tales efectos, toda vez que de los hechos no fluye el carácter de indubitable, que resulta indispensable en las manifestaciones de voluntad tácitas.

Como consecuencia, la hipótesis mencionada no se aprecia una genuina variación. De ello se deriva (i) que no sería aplicable la disciplina de los cambios al tramo de la obra ejecutado y (ii) que el comitente podría solicitar el retorno a la regla contractual original, otorgando un plazo de remediación razonable en base a la regla de la buena fe objetiva.

Otro supuesto especialmente complejo relativo a la delimitación negativa de las variaciones ocurrirá cuando el alcance de trabajos se altera por decisión de las partes, aunque sin que se verifique en aquellas un propósito lucrativo directo, esto es, la intención de producir consecuencias económicas favorables al contratista. En la hipótesis analizada, dicha función resulta común a comitente y contratista (en el caso de variaciones consensuales) o estar presente solo en el primero (en el caso de variaciones unilaterales).

El supuesto mencionado podría ocurrir cuando el comitente decide asentir la innovación del alcance con la única finalidad de colaborar con el contratista, quien podría afrontar situaciones de incumplimiento o dificultades que pongan en peligro la ejecución regular del proyecto.

Ilustraremos la referida hipótesis mediante un ejemplo. Conforme a la línea base del

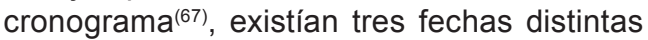
para el inicio de los frentes "A", "B" y "C" de una misma obra. Sin embargo, se verificó que el contratista no contaba con los recursos necesarios para intervenir en los frentes "B" y "C", en las oportunidades fijadas en el cronograma. Ante tal circunstancia, el contratista propuso, a manera de solución, adelantar la ejecución del frente " $A$ " (para el que sí se encontraba listo) y postergar la ejecución de los otros dos, de modo tal que no se traslapen. De este modo, el constructor tendría a disposición los recursos necesarios para ejecutar los tres frentes y podría culminar oportunamente con la obra. Tras evaluar la propuesta, y en vista que un cambio de proveedor afectaría materialmente los plazos con su propio cliente, el comitente decidió aceptar la medida propuesta por su contraparte ${ }^{(68)}$.

(64) Con todo, el propio autor plantea un ejemplo del todo excepcional (pero no por ello menos interesante) en el que sí podría existir una variación válida respecto a un trabajo que ya conforma el alcance contratado. Se trata del caso en que el contratista recibe una instrucción para proceder con ciertas actividades, frente a lo cual, el referido destinatario procede a calificar dicho requerimiento como un adicional y, bajo tal premisa, rechaza su realización sin un suplemento de precio. Frente a ello, el propietario acepta realizar el pago en semejantes condiciones.

(65) A una conclusión semejante han llegado los estudiosos del Common Law, quienes consideran que la promesa de ejecutar trabajos que una parte ya está obligada a ejecutar bajo su contrato existente no cuenta con sufficient consideration y, por ende, resulta inejecutable (Callahan 2005, 21; Bailey 2016, 647).

(66) La tolerancia o patientia es la inercia (entendida como falta de reacción, comportamiento omisivo, inacción verbal o sonora atribuible al sujeto) que, conforme a las circunstancias o a la existencia de situaciones antecedentes, determina una situación desventajosa o perjudicial para quien incurra en ella.

(67) El cronograma es aquel documento contractual que, además de ser una herramienta de seguimiento y control del desarrollo de la obra, "describe el orden lógico en que se deberán ejecutar las diversas actividades del proceso constructivo con miras a obtener el resultado previsto y que, en tanto dicho proceso es de ejecución diferida en el tiempo, que implica y supone una interpendencia lógica de dichas actuaciones, tanto del mandante como del propio contratista" (Fleischmann \& León, 2017, 101 y 102).

(68) Son dos las explicaciones que podrían tejerse sobre sobre hipótesis como la mencionada. En primer lugar, es posible señalar que se tratan de cambios verdaderos y efectivos, pero acordados únicamente para asistir al contratista en dificultades y no para que el propietario obtenga ventajas (Duncan Wallace, 1995, 893). Se trataría, así, de una suerte de variación atípica, que cuenta con un propósito de favorecer la posición del contratista y evitar el perjuicio del proyecto. En segundo lugar, es posible plantear que la hipótesis planteada no configura una variación en absoluto, sino de un trabajo contingentemente necesario que, desde una interpretación correcta del contrato, formaba parte de las obligaciones del contratista desde un inicio (Duncan Wallace, 1995, 893). 
En la hipótesis planteada se presentan dos componentes sine qua non de las variaciones: el negocio jurídico constitutivo y la alteración de la línea base del alcance. En efecto, tras haber aceptado (y no solo tolerado) los cambios en la secuencia constructiva del proyecto, el comitente no podría desconocer su asentimiento y pretender retornar a la línea base inicial del cronograma. Tras dicha aceptación se habrá formado un consentimiento válido de un contrato modificatorio y las partes se hallarán bajo el manto del pacta sunt servanda. De otro lado, se constata una genuina repercusión en la secuencia constructiva y en las fechas establecidas en el cronograma línea base. Sin embargo, a diferencia de lo que ocurre en las variaciones estándares o típicas (esto es, remunerables), el acuerdo constitutivo de la variación no contó con el propósito común dirigido a impactar los términos comerciales (precio y plazo), sino que tuvo una función económica de asistencia (colaboración con el contratista que atravesaba dificultades financieras). Al no presentar una función típicamente lucrativa, el contratista no podrá obtener un incremento de remuneración aun cuando incurra en mayores costos directos e indirectos.

De lo mencionado se deduce que la intención del autor o autores de la variación dirigida a impactar los términos comerciales de la operación (como la remuneración y plazo) no es un elemento constante, sino coyuntural en aquella categoría. Ciertamente, en el contexto de las operaciones de construcción, dada la naturaleza de los intereses involucrados y las características de los actores, podría argumentarse razonablemente la presunción de una función lucrativa. Sin embargo, como se ha tenido oportunidad de ver, es posible que de las circunstancias concretas se desprenda la existencia de variaciones en que semejante función no se encuentra presente. Ello ocurriría, por ejemplo, cuando el cambio introducido obedece a un propósito de asistencia al contratista. Escenarios como el descrito representan genuinas variaciones, aunque por su carácter no remunerable, ameritan el calificativo de atípicas.

Como último punto del presente apartado, en vista de su frecuencia en la praxis transaccional, vale la pena mencionar, aunque sea tangencialmente, el escenario conformado por lo que la jurisprudencia americana denomina constructive change orders y constructive acceleration, cuyas traducciones más fidedignas -según creemos- vendrían a ser la de órdenes de cambio inferidas y aceleración inferida.

Tales supuestos se caracterizan por la presencia de un impasse: propietario y contratista asumen posturas contrapuestas respecto a si una actividad forma o no parte del alcance contratado. Mientras el primero sostiene que se trata de trabajos ya remunerados por el contrato (y, por lo tanto, exigibles), el contratista lo objeta y se niega a realizarlos sin una retribución adicional $y$, a menudo, sin una ampliación de plazo.

Para que una hipótesis de esta naturaleza se configure necesita de la concurrencia de diversos componentes. En primer lugar, se requiere que el propietario (y no el contratista) actúe de una forma que a la postre se revele como inconsistente con los términos del contrato, recayendo una situación de incumplimiento (Duncan Wallace 1995, 923). Y es que si la pretensión del comitente contase con amparo contractual, nos encontraríamos frente a un simple incumplimiento obligacional del contratista ${ }^{(69)}$.

En segundo lugar, como consecuencia de la actuación irregular del comitente, el contratista "debe ejecutar sus trabajos de forma más costosa o incurrir en demoras adicionales que el contratista EPC razonablemente pudo haber anticipado cuando celebró el contrato EPC" (Steinberg 2017, 175). Se trata entonces indudablemente de una alteración del alcance originalmente convenido.

Finalmente, en las hipótesis ahora analizadas, el comitente suele ejercer cierta coerción fáctica sobre el contratista, tal como vendría a ser la amenaza (que a la postre se revela como ilegítima) de resolver el contrato, aplicar penalidades o ejecutar garantías. En virtud de tales circunstancias, el contratista se ve comercialmente arrastrado a ejecutar los trabajos controvertidos, sin que razonablemente cuente con oportunidad de negarse. Luego, frecuentemente el deudor opta por ejecutar tales prestaciones bajo protesto ${ }^{(70)}$.

En aquellas hipótesis donde concurren los requisitos mencionados los contratistas suelen reclamar mayor remuneración y plazo alegando haber sido forzados por el propietario a la modificación de su scope of works.

Algún autor (Steinberg 2017, 175) ha enumerado los casos clásicos de constructive change orders y constructive acceleration,

Por nuestra parte, consideramos correcta la primera alternativa, en tanto la exigibilidad de la alteración obedece a las decisiones voluntarias de las propias partes.

(69) De este modo, Steinberg $(2017,176)$ sostiene correctamente que si el propietario actúa en base a un derecho contractual no se configurará esta hipótesis.

(70) Una forma distinta, y seguramente más eficiente de gestionar el impasse, hubiese sido que el propietario emita una "instrucción que no es vinculante si el trabajo ordenado fuese un cambio". De esta manera, el contratista podrá asumir los trabajos con la seguridad que le brinda la instrucción otorgada y la cuestión sobre si debe o no realizarse un pago adicional será resuelta posteriormente (Sergeant \& Wieliczko, 2014, 23 y 31). 
clasificándolos según el propietario haya incurrido en alguno de los siguientes eventos:

- solicitar trabajos no incluidos en el contrato EPC;

- proveer documentos técnicos de diseño, materiales o equipamiento inadecuado;

- solicitar que los trabajos sean ejecutados de forma más costosa que la necesaria;

- aplicar estándares de calidad más altos que aquellos vinculantes según el contrato EPC;

- obligar al contratista EPC a acatar una interpretación errónea del contrato EPC;

- negar una ampliación de plazo justificada, lo cual ocasiona que el contratista EPC requiera acelerar los trabajos innecesariamente; $y$,

- requerir al contratista EPC ejecutar los trabajos fuera de la secuencia programada.

A continuación mencionaremos un caso que podría encajar como una constructive acceleration. La empresa Antares y Wiracocha Contratistas celebraron un contrato de construcción (el "Contrato") para el suministro e instalación de cien paneles solares destinados a un parque eólico ubicado en la localidad de Ica. El precio total del Contrato ascendió a USD \$ 800000000.

De conformidad con el cronograma convenido, Wiracocha debía tener acceso al sitio de las obras el 10 de julio de 2016, así como culminar con las pruebas integradas de los paneles el 30 de enero de 2017. El cumplimiento oportuno del contratista era crítico para Antares pues, frente al Estado Peruano, aquella tenía como fecha máxima para la entrega de los trabajos el 14 de febrero de 2017. En caso de incumplimiento de dicha obligación, el Estado le aplicaría a Antares una penalidad moratoria diaria ascendente a USD \$ 7500 00. Dicho de otra manera, la demora de Wiracocha (bajo el Contrato) ocasionaría la demora penalizable de Antares (bajo el contrato de concesión frente al Estado).

Es el caso que, por la presencia de otros subcontratistas hasta finales de setiembre de 2016, Antares recién pudo darle acceso al Sitio a Wiracocha a finales de octubre de 2016. Ante ello, y alegando un impacto en la ruta crítica de su cronograma, el contratista solicitó una ampliación del plazo del contrato por un tiempo igual a la demora en la entrega del Sitio. Sin embargo, Antares no solo rechazó el mencionado reclamo, sino que señaló lo siguiente:

- las demoras de sus subcontratistas no le son imputables a aquella, toda vez que constituyeron un hecho determinante de tercero,

- solicitó expresamente a Wiracocha culminar con las instalaciones de los paneles solares el 30 de enero de 2017 (fecha límite original), en virtud del principio pacta sunt servanda; $y$,

- responsabilizó a Wiracocha de las eventuales penalidades moratorias que el Estado Peruano le aplique a Antares en caso de atrasos en las pruebas de los paneles, afirmando que no dudaría en ejecutar la carta fianza de fiel cumplimiento para tales efectos.

Ante semejante situación, el contratista optó por acelerar bajo protesto las actividades constructivas programadas con la finalidad de culminar las pruebas de los paneles solares el 30 de enero de 2017 y evitar quedar expuesto a los riesgos mencionados anteriormente. Para tal efecto, incrementó significativamente el personal movilizado al sitio, lo cual impactó el presupuesto generando un sobrecosto ascendente a USD \$ 1000 000.00.

Como se aprecia, en el caso concurren todos los requisitos de la figura ahora analizada, quedando pendiente la determinación de si se trata de una hipótesis asociada a las variaciones. En nuestra opinión, calificar a las constructive change orders y constructive accelerations como genuinas variaciones pasa por determinar si en semejantes hipótesis estamos o no frente a un negocio jurídico modificativo (unilateral o contractual) que innove la línea base del alcance.

En ciertos sistemas jurídicos del Common Law, probablemente la noción de acuerdo contractual sea lo suficientemente flexible como para englobar los escenarios mencionados. Empero, dudamos que la solución descrita pueda ser trasladada a nuestro sistema. Si se define al acuerdo como fusión de voluntades declaradas o como la adhesión recíproca de las partes respecto a un autorreglamento de intereses, se deberá descartar la presencia de aquella noción en aquellos casos en que ambas partes del contrato asumen posiciones antagónicas respecto a un punto comercial tan elemental como la pertenencia o no de una actividad a la línea base del alcance.

Es interesante destacar que este mismo razonamiento se aprecia en ciertas resoluciones de tribunales del Common Law, como la Supreme Court of Canada en el caso Peter Kiewit \& Sons vs. Eakins Construction Ltd. (1960), según la cual resulta "imposible derivar un nuevo contrato cuando ambas partes mantuvieron posiciones contrarias cuando el trabajo fue ejecutado (...)"(71).

En suma, consideramos que las constructive change orders y constructive accelerations en el Perú no dan lugar a una variación propiamente

(71) En ese sentido, el referido tribunal explica que el remedio adecuado del subcontratista estaba dado por el cumplimiento. 
dicha, sino, eventualmente, a reclamos resarcimiento de daños y perjuicios del comitente por incumplimiento contractual(72).

\subsection{Una propuesta de definición}

En virtud de las consideraciones expuestas en el presente trabajo, no nos queda sino sintetizar lo que creemos es la noción técnicojurídica de variación del contrato de construcción. A nuestro juicio, esta última se encuentra conformada por dos componentes lógicos concurrentes.

En primer lugar, una variación requiere la modificación de un contrato de construcción derivada de la celebración un negocio jurídico modificatorio existente, válido y eficaz. Este negocio jurídico puede ser unilateral (por ejemplo, ius variandi del comitente) o consensual (contrato). En segundo lugar, la variación requiere que, como consecuencia del negocio modificativo mencionado anteriormente, se altere, dentro de ciertos parámetros constituidos por la superación del límite interno y por la no superación del límite externo, la línea base del alcance de trabajos (scope of works).

Al respecto, el alcance de trabajos debe ser definido como el conjunto de obligaciones asumidas por el contratista asociadas al producto (resultado global de trabajo) comprometido por aquel frente al comitente. Las actividades comprendidas en el alcance se encuentran dentro de la esfera de riesgos del contratista y se entienden remuneradas por el precio total a cargo del comitente. Aquellas actividades pueden subdividirse en trabajos necesarios, instrumentales, contingentemente necesarios y heterónomos.

De manera ejemplificativa y no limitativa, son innovaciones que pueden dar lugar a variaciones aquellas que recaen en las cantidades, calidad, especificaciones, dimensiones, secuencia constructiva, plazos, modalidades de ejecución o métodos constructivos, forma, carácter o posición de los trabajos primitivos; así como aquellas innovaciones en las actividades de cooperación y trabajos temporales del contratista.

Los mencionados requisitos pueden ser expresados gráficamente de la siguiente manera:

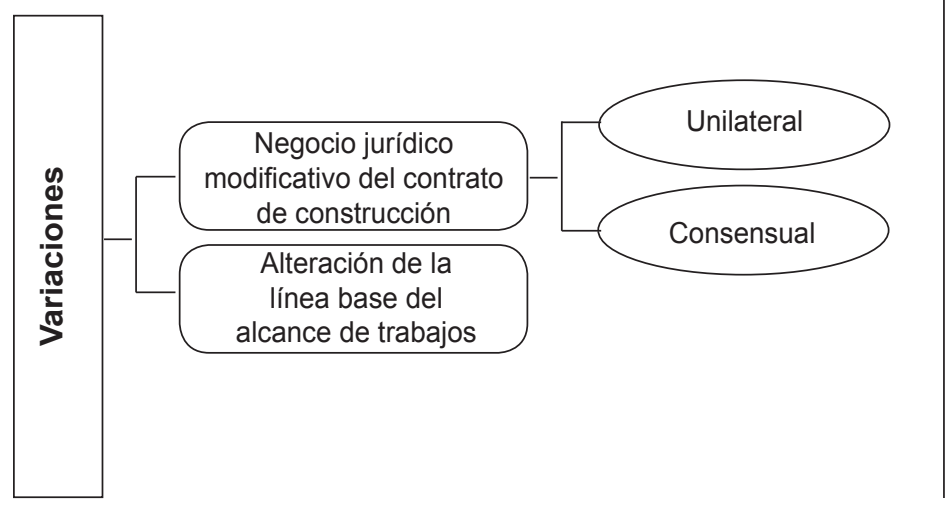

Ahora bien, es posible constatar que la función del negocio modificativo destinada a impactar los términos comerciales de la operación (como la remuneración y el plazo originales) es un elemento absolutamente frecuente en la praxis transaccional. Empero, dicho requisito no es constante, sino coyuntural en las variaciones (en ciertas ocasiones se encuentra ausente).

Cuando el mencionado elemento se encuentre presente, nos encontraremos frente a variaciones típicas o remunerables, cuyas consecuencias jurídicas se encuentran dadas por las repercusiones en los términos comerciales de la operación (es decir, impactarán, como mínimo, el precio total y el plazo convenidos). Cuando se encuentre ausente la función comercial típica, estaremos frente a variaciones atípicas. Estas últimas, que suelen estar asociadas a cambios introducidos con la finalidad de asistir a una parte que atraviesa dificultades, carecerán de las consecuencias comerciales mencionadas anteriormente.

\section{Conclusiones}

a) Son causas intrínsecas de variaciones en los proyectos de construcción:

- los errores imputables a los profesionales involucrados en el proyecto (cliente, comitente, diseñador y contratista);

- el tiempo insuficiente del que disponen los profesionales para la elaboración de los estudios técnicos y el diseño;

- la generación de información más exacta sobre el proyecto en una oportunidad posterior a la elaboración de los documentos;

- la falta de coordinación entre los profesionales involucrados;

- Ia información inadecuada proporcionada por los partícipes del proyecto;

- la asunción de tareas ajenas a su expertise por profesionales vinculados a los diversos partícipes;

- la falsedad e inobservancia de declaraciones y garantías, así como el

(72) Duncan Wallace explica que las cortes de los sistemas del Common Law han solucionado casos semejantes aplicando la teoría de la implied promise, unconscionability o enriquecimiento sin causa, siendo que el autor muestra cierta predilección por el remedio mencionado en segundo lugar (1995, 920 y siguientes). 
incumplimiento de obligaciones y cargas de las partes, especialmente aquellas que constituyen actividades precedentes de otras;

- la discontinuidad de los documentos contractuales iniciales debida a la demora en el proceso de negociación, frecuentemente influenciado por razones políticas o burocráticas;

- las necesidades de financiamiento para la continuidad de proyectos, las cuales suelen requerir un análisis técnico para determinar su bancabilidad;

- la necesidad de optimización del diseño en base a información generada u obtenida en el desarrollo del proyecto;

- las propuestas del contratista en un contexto de ingeniería de valor;

- los cambios en la apreciación estética y de conveniencia del comitente o del cliente;

- las vicisitudes legales y/o físicas previsibles;

- a demora en la emisión de licencias y permisos ambientales, regulatorios, arqueológicos asociados al sitio;

- la divergencia previsible entre las condiciones del sitio esperadas y aquellas reales;

- las dificultades asociadas a la entrega área del emplazamiento y de sus accesos, a la secuencia de operaciones y a las restricciones en el tiempo de trabajo; y,

- la corrupción.

b) Entre las principales causas extrínsecas de las variaciones tenemos las siguientes:

- cambios en las condiciones físicas, tales como eventos de caso fortuito o fuerza mayor o los eventos geológicos extraordinarios;

- razones sociales, comunitarias y ambientales;

- cambios normativos y políticos;

- la obsolescencia de ciertos componentes del alcance o de ciertos métodos constructivos; $y$,

- los cambios en las condiciones de mercado.

c) En cuanto a la noción de variación, es posible afirmar que, en el marco de un contrato de construcción, aquella categoría se encuentra conformada por los siguientes dos componentes lógicos conjuntos:

- La modificación válida y eficaz a un contrato de construcción producto de la celebración un negocio jurídico unilateral (del comitente) o un contrato (entre comitente y contratista).

- El hecho que, como consecuencia del negocio modificativo mencionado, se altere la línea base del alcance de trabajos a cargo del contratista en aspectos como las cantidades de trabajos, su calidad, especificaciones, dimensiones, secuencia constructiva, modalidades de ejecución o métodos constructivos, cooperación instruida, trabajos temporales, forma, carácter 0 posición del proyecto constructivo o sus características convenidas.

Dicha alteración no necesariamente implica trabajos físicos o corporales por parte del contratista, sino que bien podría suponer modificaciones en los intangibles, tales como servicios, tecnologías que conforman sistemas o subsistemas de la obra o la transferencia de derechos de propiedad intelectual. En otras palabras, la categoría que nos ocupa incidirá sobre los componentes que integran la obra constructiva, sean tangibles o intangibles.

Por su parte, si bien es absolutamente frecuente, la función del negocio jurídico modificativo destinada a impactar los términos comerciales originalmente acordados por las partes, es un componente meramente coyuntural que solo estará presente en las denominadas variaciones típicas. Las consecuencias jurídicas de tales variaciones serán las repercusiones en la remuneración y el plazo originales. Empero, pueden existir genuinas variaciones (atípicas) que prescindan de la función económica descrita y de sus repercusiones jurídicas.

d) De la síntesis mencionada en el párrafo anterior, se desprende también la centralidad del alcance de trabajos (scope of works) en nuestra indagación. Al respecto, cabe señalar que aquel se encuentra conformado por las obligaciones asumidas por el contratista frente a su contraparte asociadas al producto (resultado global de trabajo) comprometido. Semejantes actividades se ubican necesariamente, sea por influencia contractual o legal, dentro de la esfera de riesgos del contratista.

A mayor detalle, el alcance se compone de las siguientes subcategorías:

- Trabajos necesarios. Son actividades constructivas derivadas directamente de los planos, especificaciones técnicas y otros documentos contractuales (entendiendo por estos aquellos de los cuales emanan derechos y obligaciones para las partes). 
- Trabajos instrumentales. Es el grupo de actividades que, si bien no se encuentran explícitamente previstas en los documentos contractuales, resultan necesarias o subordinadas para la realización funcional, idónea y segura de los trabajos necesarios.

- Trabajos contingentemente necesarios. Se trata de actividades constructivas cuya necesidad de ejecución resulta incierta, en tanto depende de circunstancias sobrevinientes (o de cognoscibilidad sobreviniente) asociadas a la esfera de riesgos a cargo del contratista. Empero, en caso la necesidad de realizar estas actividades se haga patente, serán instrumentales, necesarias o heterónomas.

- Trabajos heterónomos. Son aquellos cuya exigibilidad no deriva directamente del programa contractual dispuesto por las partes, sino de fuentes heterónomas de integración, tales como las leyes aplicables, los usos y costumbres (es decir, de las buenas prácticas profesionales de la ingeniería y construcción) y la buena fe objetiva.

e) Una variación, para ser tal, necesariamente deberá alterar la línea base del alcance de trabajos. A mayor detalle, dicha alteración radicará en la introducción de componentes (i) ajenos la esfera de riesgos del contratista y (ii) que no se encuentren englobados dentro de los trabajos necesarios, instrumentales, contingentemente necesarios ni heterónomos.

f) De otro lado, la modificación capaz de generar una variación debe superar un límite externo y mantenerse dentro de un límite externo.

Una innovación del alcance exorbita el límite externo (y, por ende, no puede dar lugar a una variación) en alguna de las dos siguientes situaciones:

- Cuando supera toda previsión razonable de las partes al momento de contratar. Como consecuencia, su incorporación dará lugar a un contrato de construcción ajeno al primigenio, al cual frecuentemente reemplazará generando una novación objetiva. Para tales efectos, debe tenerse en cuenta no solo el impacto aislado de una variación, sino también las repercusiones imputables a una multiplicidad de modificaciones, aunque sean sucesivas y no coetáneas.

- Cuando constituye una obra nueva complementaria, es decir, una prestación consensuada que cuenta con individualidad propia y con su respectivo proyecto. Estas alteraciones no menoscaban el proyecto original, sino que lo complementan y facilitan.

No constituyen variaciones por no superar el límite interno las siguientes hipótesis:

- Las simples instrucciones, es decir, aquellas comunicaciones de autoría del comitente o del supervisor a través del cual se imparte al contratista una orden (de cumplimiento obligatorio) relativa a la ejecución regular de los trabajos que forman parte del alcance. Sin embargo, la relación entre instrucción y variación es coyuntural, pues puede existir instrucciones que -sin dejar talescontengan variaciones, por exorbitar el alcance primitivo.

- Las prestaciones de concreción a cargo del contratista, que operan dentro de parámetros o lineamientos derivados de los documentos contractuales y, por ende, forman parte del alcance de trabajos.

g) En cuanto a su ámbito temporal, las variaciones tienen lugar en la etapa de ejecución del contrato, esto es, en el arco de tiempo que transcurre desde su celebración hasta la consumación de su vigencia.

De ello se desprende que, antes de la formación del contrato, los cambios que el titular del proyecto efectúe en los documentos técnicos (aun no contractuales) no son variaciones. Ello se debe a que en tal supuesto no existe aún un acuerdo contractual generador de obligaciones para las partes respecto a cuyo scope of works operen las modificaciones. En tales casos nos encontraríamos frente a meros ajustes a los documentos técnicos precontractuales cuya versión final o actualizada será la única que se incorpore al contrato de construcción, en caso el contratista brinde su ulterior aceptación.

De otro lado, si la fuerza vinculante del contrato ha decaído (por consumación o alguna forma de extinción patológica), tampoco podría existir una variación, en tanto las variaciones presuponen un vínculo vigente entre las partes.

h) En cuanto a la delimitación negativa de la hipótesis analizada, no son variaciones del alcance de trabajos:

- las desviaciones del contratista, aun cuando hubiesen sido toleradas por el comitente (sin dar lugar a una manifestación de voluntad tácita ni presunta);

- las actividades de remediación de defectos;

- las mal denominadas variaciones menores (es decir, aquellas relativas a detalles secundarios cuya necesidad y oportunidad se manifiesta solo en 
el curso de ejecución y que permanecen comprendidas dentro del orden normal de cosas);

- el incremento de dificultad u onerosidad de las prestaciones del contratista;

- la obligación cantidades de trabajo divergentes respecto a lo previsto en la planilla de metrados (o documento equivalente), cuando el contratista asumió dicho riesgo;

- las iniciativas de las partes; ni,

- las órdenes de cambio inferidas (constructive change orders) o aceleración inferida (constructive acceleration).

\section{Referencias bibliográficas}

Adriaanse, J. 2016. Construction contract law, Londres, Palgrave. https://doi.org/10.1057/978-1-137-00959-3

Albhaisi, M., Tayeh, B. \& El-Hallaq, K. 2016. Factors causing variation orders in construction projects in Gaza Strip (Case study: Qatar projects). International Journal of Engineering and Management Research, 6 (5), 262-270.

Arain, F \& Low, S 2005. The potential effects of variation orders on institutional building projects. Facilities, 23 (11), 496-510. https:// doi.org/10.1108/02632770510618462

Arias-Schreiber, Max, Cárdenas, C. \& Martínez, E. 2006. Exégesis del Código Civil peruano de 1984. 1, Lima, Perú: Gaceta Jurídica.

Arias-Schreiber, Max. 2015. Contrato de obra. En Revoredo, D. (Compiladora) Código Civil: Exposición de Motivos y Comentarios (519-544), 6, Lima, Perú: Thomson Reuters.

Bailey, J. 2016. Construction Law, 1, Nueva York, Estados Unidos: Informa Law. https://doi.org/10.4324/9781315755465

Bianca, M. 2007. Derecho civil 3. El contrato. Bogotá, Colombia: Universidad Externado de Colombia.

Callahan, M. 2005. Construction change order claims. Nueva York, Estados Unidos: Aspen.

Campos, A. 2008. El contrato de Obra Pública. Lo que no dice la ley de Contrataciones del Estado, pero debería decir. Revista del Círculo de Derecho Administrativo 5, 297-308.

Castillo, M. \& Castro, L. 2008. El Contrato de obra. En Autores Varios. Libro Homenaje a Felipe Osterling Parodi (919-987), 2, Lima, Perú: Palestra.

Cervale, M.C. 2011. La struttura dell'appalto. En Rescigno, P. \& Gabrielli, E., Trattato dei Contratti (Turín, Italia: UTET), 95-118.

Champion, R. 2007. Variations, time limits and unanticipated consequences. Un ensayo basado en el segundo lugar ocupado en la SCL Hudson Prize essay competition 2006, presentado en la reunión de la Society of Construction Law en Londres, el 1ero de Mayo de 2007, s/n. Recuperado de www.scl.org.uk.
De Almagro, I. \& Klee, L. 2017. Los contratos internacionales de construcción. FIDIC. Madrid, España: Wolters Kluwer.

De la Puente, M. 2007. El contrato en general. Comentarios a la sección primera del libro VII del Código civil, 2, Lima, Perú: Palestra.

Díez-Picazo, L. 2007. Fundamentos del Derecho Civil Patrimonial, 4, Madrid, España: Civitas.

Dopazo, P. 2015. La mercantilidad del contrato de obra por empresa como innovación regulatoria del nuevo Código Mercantil. Los contratos de obras de construcción/edificación. En Autores Varios. Estudios sobre el futuro Código Mercantil. Libro Homenaje al profesor Rafael Illescas Ortiz (1307-1325), Getafe, España: Universidad Carlos III de Madrid.

Duncan Wallace, I. 1995. Hudson's Building and Engineering Contracts. Including the Duties and Liabilities of Architects, Engineers and Surveyors, 1, Londres, Sweet \& Maxwell.

Ennis, C. 2015. Prospective claims for variations under FIDIC and NEC3: evidential and procedural issues. Un ensayo presentado en la conferencia inaugural de la Society of Construction Law Sudáfrica en Ciudad del Cabo, el 10 de setiembre de 2015, s/p. Recuperado de www.scl.org.uk.

Erviti, E. \& López, M. 2009. Arrendamientos de obra y de servicios, Navarra, España, Aranzadi, Thomson Reuters.

Fidic. 2017. Conditions of contract for construction, Ginebra, Suiza: FIDIC.

Fleischmann, H. \& León, J. 2017. El programa de trabajo como fuente de obligaciones en el contrato de construcción. En Figueroa, J. Derecho de Construcción. Análisis dogmático y práctico (93-115). Santiago, Chile: Universidad de los Andes.

Franco, E. 2009. Aceptación y rechazo de obras de construcción ¿rechazo por defectos menores? IUS ET VERITAS 38, 80-94.

2015. Reclamos por demoras, disrupción y aceleración en proyectos de construcción. En Marcondes, F. Temas de Direito da Construção (121-159), San Pablo, Brasil: Pini.

Goñi, M. 2015. Cuando el empresario responde casi solo por el hecho de serlo: requisitos jurisprudenciales de su responsabilidad por hecho ajeno. Revista Crítica de Derecho Inmobiliario, 750, 2342-2364. 
Gray, J \& Bravo, J. 2013. Liabilities for design defects in a collaborative, integrated digital age. Construction law international, 8, (4), 19-24.

Gudín, A.E. 2011. El «ius variandi» en las obras con ajuste alzado. Antecedentes históricos, evolución jurisprudencial y examen del derecho comparado. Anuario Jurídico y Económico Escurialense, 44, 143-172.

Guzmán, C. 2015 Manual de Contrataciones del Estado. Análisis de la Ley y su Reglamento. Lima, Perú: Gaceta Jurídica.

Hanna, A. \& Swanson, J. 2007. Risk allocation by law-cumulative impact of change orders. Journal of Professional Issues in Engineering, Education and Practice, 133 (1), 60-66.

Hernández, A. 1999. Los contratos internacionales de construcción 'llave en mano'. Granada, España: Comares.

Hibberd, P. 1986. Variations in construction contracts. Londres, Collins.

Horgué, C. 1997. La modificación del contrato administrativo de obra. El ius variandi. Madrid, España: Marcial Pons.

Hughes, W. Champion, R. \& Murdoch, J. 2015. Construction contracts. Law and management. Londres, Inglaterra: Routeledge.

Jiménez, M. 2012. La distinción entre los contratos de obras y servicios en el Derecho español (estudio comparado con el Derecho alemán). Anuario de Derecho Civil, 65 (2), 551-584.

Lamarca, A. 2008. Código Civil Alemán y Ley de Introducción al Código Civil, Madrid, España: Marcial Pons.

Linares, M. 2009. Adicionales de Obra Pública. Obra Pública y Contrato, Adicionales, Función Administrativa, Control Público, Arbitraje y Enriquecimiento sin Causa. Revista de Derecho Administrativo, 7, 175-190.

Liu, M., Ballard, G. \& Ibbs, W. 2011. Work flow variation and labor productivity: Case study. Journal of Management in Engineering, 27 (4), 236-242.

Lofthouse, S. 2011. "Change": What is it, how is it valued and who should resolve any dispute". Un ensayo presentado en los encuentros de la Society of Construction Law en Manchester, el 26 de abril, Sheffield, el 8 de junio y Cardiff el 27 de octubre de 2010, s/p. Recuperado de www.scl.org.uk.

Lyden, J. 2006. Fair valuation of variations under civil engineering and building contracts in Ireland. Un ensayo presentado en el encuentro de la Society of Construction Law y la Society of Chartered Surveyors en Cork, Irlanda, el 8 de Noviembre de 2004, s/p. Recuperado de www.scl.org.uk.

Macario, F. 2011. Integrazione del contratto. En Navarretta, E. \& Orestano, A. (Directores). Dei Contratti in generale Artículos 1350-1386 (682-721). En Gabrielli, E. (Director) Commentario del Codice Civile. Turín, Italia: Utet Giuridica.

Molina, C. \& Ríos, V. 2016. Derecho de la construcción. Santiago, (s/e).
Moscarini, L.V. 2011. I/ contratto di appalto e le figure affini. En Rescigno, P. \& Gabrielli, E., Trattato dei Contratti. I contratti di appalto privato (3-60), Turín, Italia: UTET.

Musolino, G. 2011. Variazioni concordate del progetto. En Navarretta, E. \& Orestano, A. (Directores). Dei Contratti in generale Articoli 1655-1802 (57-67). En Gabrielli, E. (Director) Commentario del Codice Civile. Turín, Italia: Utet Giuridica.

Nervi, A. 2011. Le parti del contratto. En Rescigno, P. \& Gabrielli, E., Trattato dei Contratti. I contratti di appalto privato (61-94), Turín, Italia: UTET.

Oladapo, A.A. 2007. A quantitative assessment of the cost and time impact of variation orders on construction projects. Journal of Enginerring, Design and Technology, 5, (1), 35-48.

Oliva, F. 2014. El Anteproyecto de Código Mercantil en el contexto del proceso internacional de unificación del derecho privado de los contratos. Revista de Derecho Civil, 1 , (3), 37-66.

Panetta, R. 2016. II contratto di appalto. En Lucchini Guastalla, E. (Director). Collana dei contratti. Turín, Italia: Giappichelli.

Pennington, T. 1997. Variations (change orders) in construction contracts for U.A.E. Turnkey projects. Middle East Executive Reports, 20 (3), 1-10.

Perlingieri, P. 1980. Codice civile annotato con la dottrina e la giurisprudencia, 4 (2), Turín, Italia: Utet.

Phillips, C. S. 1999. Construction contract administration. Littleton, Estados Unidos: Society of Mining, Metallurgy, and Exploration, Inc.

PMI. 2017. A guide to the Project Management Body of Knowledge (PMBOK Guide)-Sixth Edition. Newton Square, Estados Unidos: Project Management Institute.

Podetti, H. 2004. Contrato de construcción. Buenos Aires, Argentina: Astrea.

Polidori, S. 2015, Appalto. En Perlingieri, P. (Director). Trattato di Diritto Civile del Consiglio Nazionale del Notariato, Nápoles, Italia: Edizioni Scientifiche Italiane.

Powell, G. 1995. The cardinal change doctrine and its application to government construction contracts. Public Contract Law Journal, 24 (3), 377-399. 
Ramsey, V. \& Furst S. 2012. Keating on construction contracts. Londres, Inglaterra: Sweet \& Maxwell.

Rengifo, E. 2017. Las facultades unilaterales en la contratación moderna. Bogotá, Colombia: Legis.

Rescigno, P. 1988. Appalto (Diritto Privato). Enciclopedia Giuridica, 2, s/p.

Roppo, V. 2009. El contrato. Lima, Perú: Gaceta jurídica.

Rubino, D. \& ludica, G. 1992. Dell'appalto. En Galgano, F. (al cuidado de) Commentario del Codice Civile Scialoja-Branca. Boloña, Italia: Zanichelli.

Rubino, D. 1961. Dell'appalto. En Scialoja, A. \& Branca, G. (al cuidado de) Commentario del Codice Civile. Boloña, Italia: Zanichelli, Roma, Italia: Foro Italiano.

Schulze, R \& Albiez Dohrmann, K.J. 2012. Las líneas centrales del estudio comparativo del contrato de obra en Alemania y España. Anuario de Derecho Civil, 65 (2), 547-550.

Scognamiglio, C. 2008. Contratos de empresa y voluntad de los contratantes. Revista de Derecho Privado, 15, 27-40.

Scott, R. \& Kaus, J.S. 2013. Contract law and theory. Durham, Estados Unidos: Carolina Academic Press.

Sendmeyer, S. 2012. La responsabilidad por vicios en el contrato de obra del Derecho alemán. Anuario de Derecho Civil, 65, (2), 585-611.

Sergeant, M \& Wieliczko, M. 2014. Construction contract variations, Nueva York, Estados Unidos: Informa Law.

Spencer, E. A. B. 1955. Powers of direction and determination under Construction Contracts. Virginia Law Review, 41 (3), 343-361.

Steinberg, H. 2017. Understanding and negotiating EPC contracts, 1, Londres, Inglaterra: Routledge.

Supreme Court of Canada. 1960. Peter Kiewit Sons' Co. v. Eakins Construction Ltd., S.C.R. 361.
Tapia, A. 2016. El contrato de obra por empresa. Madrid, España: Reus.

Thomas, R. 2001. Construction contract claims, Nueva York, Estados Unidos: Palgrave.

Tovar, M. C \& Ferrero, V. 2007a. Obra por ajuste. (Comentario al artículo 1776 del Código Civil). En AA.VV. Código Civil comentado. Comentan 209 especialistas en las diversas materias de Derecho Civil (161-165), 9, Lima, Perú: Gaceta Jurídica.

2007b. Definición. (Comentario al artículo 1771 del Código Civil). En AA.VV. Código Civil comentado. Comentan 209 especialistas en las diversas materias de Derecho Civil (140-148), 9, Lima, Perú: Gaceta Jurídica.

2007c. Obligaciones del contratista. (Comentario al artículo 1774 del Código Civil). En AA.VV. Código Civil comentado. Comentan 209 especialistas en las diversas materias de Derecho Civil (153-159), 9, Lima, Perú: Gaceta Jurídica.

2007d. Prohibición de introducir variaciones. (Comentario al artículo 1775 del Código Civil). En AA.VV. Código Civil comentado. Comentan 209 especialistas en las diversas materias de Derecho Civil (159-161), 9, Lima, Perú: Gaceta Jurídica.

Uff, J. 2017. Construction law. Londres, Inglaterra: Sweet \& Maxwell.

Ugas, A.P. 2010. Variazioni concordate del progetto. En Luminoso, A., Codice dell'appalto privato (368-412), Milán, Italia: Giuffrè.

Unidroit, 2016. Unidroit Principles of International Commercial Contracts. Roma, Italia: UNIDROIT. Recuperado de https:// www.unidroit.org/instruments/commercial-contracts/unidroitprinciples-2016

Vallejo, F. 2007. Responsabilidad profesional en la construcción de obras. Revista Derecho del Estado, 20, 97-119.

Vásquez, Walter. 2015. Construyendo la definición de variaciones en el contrato de obra. Gaceta Civil \& Procesal Civil, 24, 85-96.

2017. Los contratos de construcción. La figura del contratista y su relación con el riesgo. Revista de Actualidad Mercantil, 5, 53-74.

Wiezel, J. 2013. The "significant change in the character of the work" clause: uncertain federalism in highway construction contracts. Public Contract Law Journal, 42 (2), 327-346).

Zuddas, G. 2010. Elementi costitutivi delll'apalto. En Luminoso, A. (al cuidado de), Codice dell'appalto privato (3-156), Milán, Italia: Giuffrè. 